\title{
WNT/beta-catenin signalling interrupts a senescence-induction cascade in human mesenchymal stem cells that restricts their expansion
}

\author{
Johannes Lehmann ${ }^{1,2,8}(\mathbb{D}) \cdot$ Roberto Narcisi $^{3}(\mathbb{1}) \cdot$ Natasja Franceschini ${ }^{1} \cdot$ Danai Chatzivasileiou ${ }^{1} \cdot$ Cindy G. Boer $^{4}$. \\ Wendy J. L. M. Koevoet ${ }^{1}$ - Diana Putavet ${ }^{5,6} \cdot$ Dubravka Drabek $^{2,7} \cdot$ Rien van Haperen $^{2,7} \cdot$ Peter L. J. de Keizer ${ }^{5,6}$. \\ Gerjo J. V. M. van Osch ${ }^{1,3}$. Derk ten Berge ${ }^{2}$ (I)
}

Received: 23 April 2021 / Revised: 18 October 2021 / Accepted: 9 November 2021 / Published online: 20 January 2022

(c) The Author(s) 2022

\begin{abstract}
Senescence, the irreversible cell cycle arrest of damaged cells, is accompanied by a deleterious pro-inflammatory senescenceassociated secretory phenotype (SASP). Senescence and the SASP are major factors in aging, cancer, and degenerative diseases, and interfere with the expansion of adult cells in vitro, yet little is known about how to counteract their induction and deleterious effects. Paracrine signals are increasingly recognized as important senescence triggers and understanding their regulation and mode of action may provide novel opportunities to reduce senescence-induced inflammation and improve cell-based therapies. Here, we show that the signalling protein WNT3A counteracts the induction of paracrine senescence in cultured human adult mesenchymal stem cells (MSCs). We find that entry into senescence in a small subpopulation of MSCs triggers a secretome that causes a feed-forward signalling cascade that with increasing speed induces healthy cells into senescence. WNT signals interrupt this cascade by repressing cytokines that mediate this induction of senescence. Inhibition of those mediators by interference with NF- $\mathrm{KB}$ or interleukin 6 signalling reduced paracrine senescence in absence of WNT3A and promoted the expansion of MSCs. Our work reveals how WNT signals can antagonize senescence and has relevance not only for expansion of adult cells but can also provide new insights into senescence-associated inflammatory and degenerative diseases.
\end{abstract}

Keywords Multipotent stromal cells $\cdot$ Cell cycle $\cdot$ Secondary senescence $\cdot$ Paracrine senescence

\section{Introduction}

Following irreparable damage, healthy cells can enter a state of stable cell cycle arrest termed senescence [1]. Senescence regulates tissue growth during development and can repress

Gerjo J. V. M. van Osch and Derk ten Berge contributed equally.

Derk ten Berge

d.tenberge@erasmusmc.nl

1 Department of Otorhinolaryngology and Head and Neck Surgery, Erasmus MC, University Medical Center, Rotterdam, The Netherlands

2 Department of Cell Biology, Erasmus MC, University Medical Center, Rotterdam, The Netherlands

3 Department of Orthopaedics and Sports Medicine, Erasmus MC, University Medical Center, Rotterdam, The Netherlands

4 Department of Internal Medicine, Erasmus MC, University Medical Center, Rotterdam, The Netherlands
5 Center for Molecular Medicine, Section Molecular Cancer Research, Division LAB, University Medical Center Utrecht, Utrecht, The Netherlands

6 Department of Genetics, Erasmus MC, University Medical Center, Rotterdam, The Netherlands

7 Harbour Biomed, Rotterdam, the Netherlands

8 Present Address: Center for Molecular Medicine, Section Molecular Cancer Research, Division LAB, University Medical Center Utrecht, Utrecht, The Netherlands 
expansion of transformed cells [2-4] but also limits somatic cell expansion, contributing to ageing and hampering cellbased therapies [5-8]. Several stressors can induce senescence, including shortening telomeres, DNA damage, mitochondrial deterioration, and oncogene expression [1]. Over the last decade, evidence accumulated that senescent cells affect their environment via their secretome, often termed the senescenceassociated secretory phenotype (SASP) (reviewed in [9]), consisting mostly of pro-inflammatory cytokines, proteases and insulin-growth factor-binding proteins $[10,11]$. A subset of SASP factors induces proliferation during wound healing and development [3, 4, 12-14]. However, in other circumstances, SASP factors mediate the spread of senescence to surrounding cells [15-21].

Recently, it has been shown that senescent mesenchymal cells can systemically induce senescence via paracrine signalling, leading to increased frailty and reduced life span [8] and reduced regenerative capacity [22], although it remains unclear how this process is regulated. Mesenchymal stem cells (MSCs, also known as multipotent stromal cells) have been intensely studied for tissue engineering due to their ability to form fat, cartilage and bone-like tissues [23], and for the anti-inflammatory, repair-inducing properties of their secretome [24-27]. However, MSCs rapidly undergo senescence in vitro, not only limiting the numbers that can be obtained for clinical applications [5, 28-32], but creating a source of SASP factors that can drive frailty and neoplastic progression [8,33], obliterate the anti-inflammatory capacities of MSCs [34] and aggravate inflammation-associated diseases, such as atherosclerosis and osteoarthritis [35, 36]. Understanding the mechanisms that induce senescence in MSCs and cause the production of SASP factors will not only facilitate MSC-based clinical applications but may provide insight into the role of paracrine senescence in tissue homeostasis, regeneration, cancer and degenerative diseases.

We previously showed that WNT signals support the expansion and developmental potential of embryonic chondrogenic progenitors $[37,38]$ and of MSCs during prolonged culture $[32,39]$. The WNT/ $\beta$-catenin signalling pathway supports the self-renewal of many types of stem cells, including embryonic stem cells [40], intestinal stem cells [41], and hair follicle and epidermal stem cells [42], by inhibiting their differentiation and promoting their proliferation (reviewed in [43]). In contrast to these earlier examples, we demonstrate here that WNT signals support MSC proliferation and developmental potential not by regulating proliferation and differentiation but by protecting the cells from the deleterious effects of senescence.

\section{Results}

\section{WNT3A counteracts entry of MSCs into senescence}

The proliferation of human bone marrow-derived MSCs rapidly declines over time, and this can be counteracted by supplementation with WNT3A (Fig. 1a, Supplementary Fig. 1a) confirming our previous findings [32]. To understand how WNT signalling prevented the decline of MSC proliferation, we performed whole transcriptome analysis of early passage (P1) MSCs and of MSCs maintained until passage four (P4) with WNT3A or vehicle control (Fig. 1b). Pathway analysis identified pathways associated with DNA repair and cell cycle regulation as down-regulated with passage in vehicle and up-regulated by WNT3A (Fig. 1c), whereas pathways associated with senescence were up-regulated with passage in vehicle and down-regulated by WNT3A (Fig. 1d). To quantify these changes, we constructed gene sets for cell cycle associated genes (set based on [44]), for DNA repair regulating genes (set based on [45]) and for SASP genes (based on [10]). Gene set enrichment analysis then revealed that the DNA repair and cell cycle gene sets were significantly enriched among genes up-regulated with WNT3A, whereas the SASP gene set was significantly enriched among genes downregulated with WNT3A (Fig. 1e). Inspection of individual gene expression levels showed that WNT3A maintained the expression levels of DNA repair and cell cycle gene sets over time in culture while they mostly declined in the absence of WNT3A (Fig. 1f, g). The majority of SASP factors $(37 / 60)$, on the other hand, increased over time in the absence of WNT3A but was repressed in its presence (Fig. 1h). Impaired cell cycle progression, decline in DNA repair gene expression and the SASP are key aspects of senescence [46, 47]. Accordingly, the expression of positive and negative senescence markers (including panels from $[48,49]$ ) was consistent with MSCs entering senescence over time, while this was counteracted by the presence of WNT3A (Fig. 1i, Supplementary Fig. 1b, c). Of note, expression of WNT family ligands and WNT/betacatenin signalling target genes did not decrease over time in vehicle cultured MSCs (Supplementary Fig. 1d-f). This suggests that the increase in senescence is not caused by a decline in endogenous WNT ligands and is consistent with our previous findings that inhibition of endogenous WNT ligands does not affect MSC proliferation [32]. Together, these observations suggest that WNT3A counteracts the entry of MSCs into senescence.

To follow up on the findings regarding DNA damage repair in our sequencing data, we stained for phosphorylated Histone 2A Family member $\mathrm{X}(\gamma \mathrm{H} 2 \mathrm{AX})$, which is elevated after ATM activation and required for double-strand 

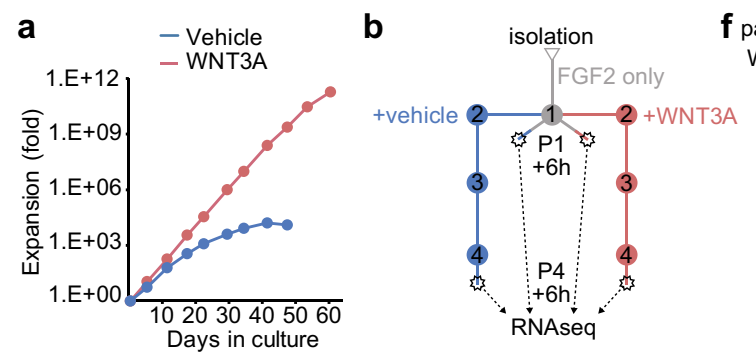

C

down: P1 $\rightarrow$ P4 (vehicle) \& up: WNT3A vs. vehicle (P4)

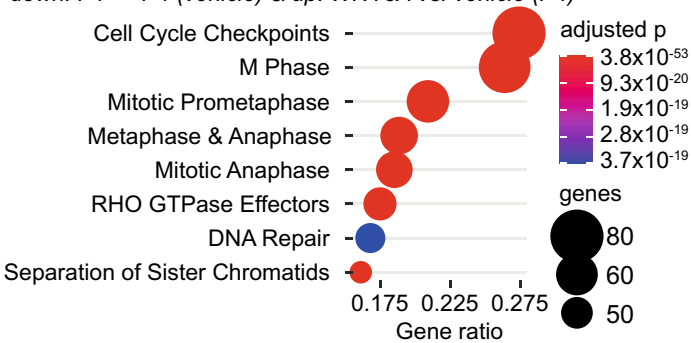

passage $\begin{array}{llll}1 & 1 & 4 & 4\end{array}$

WNT3A - + +

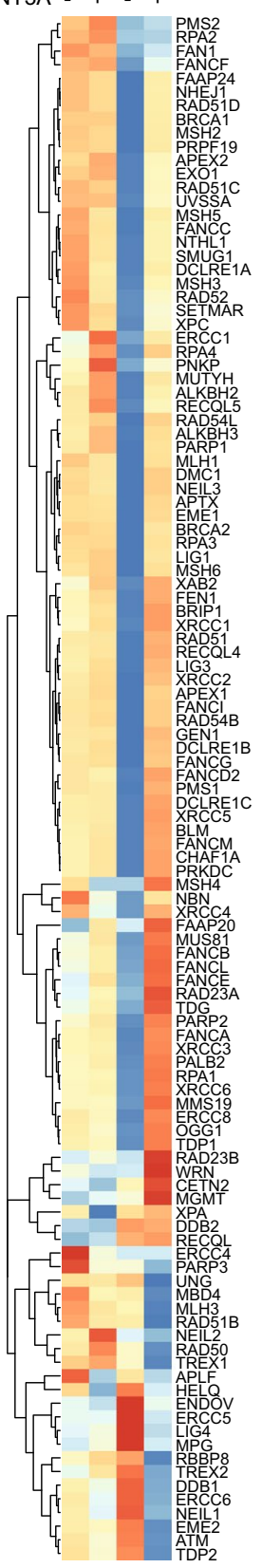

g passage $1 \begin{array}{lll}1 & 4 & 4\end{array}$ WNT3A - + - +
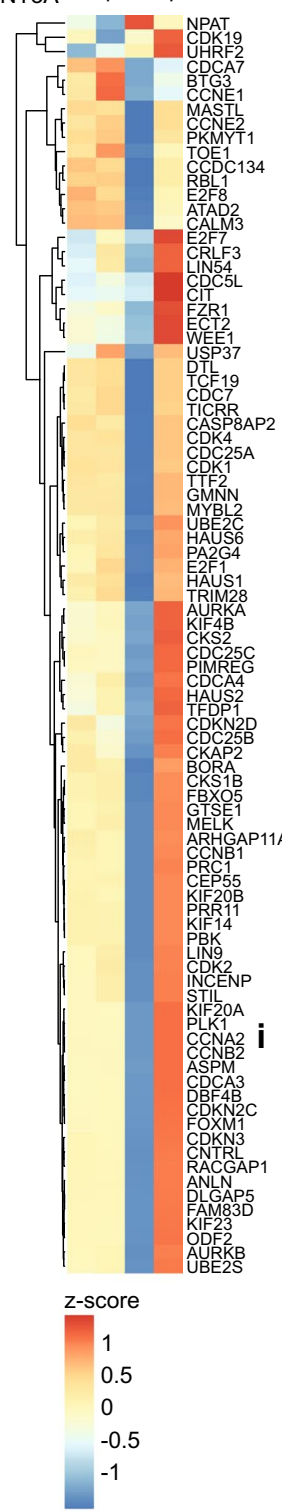

h passage $1114 \quad 4$

WNT3A -

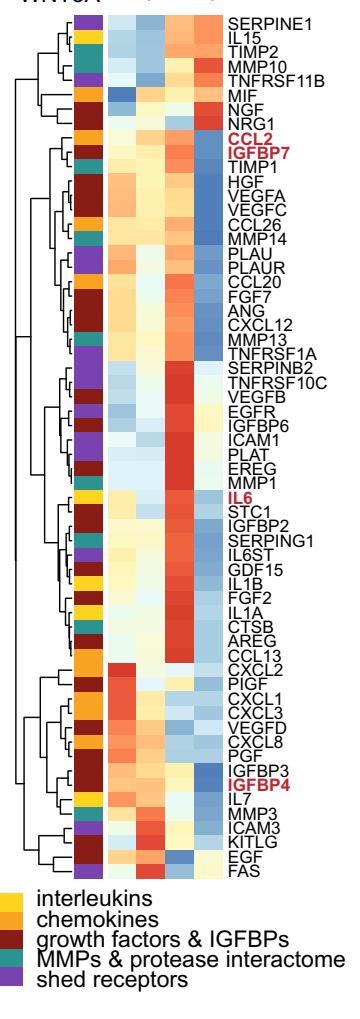

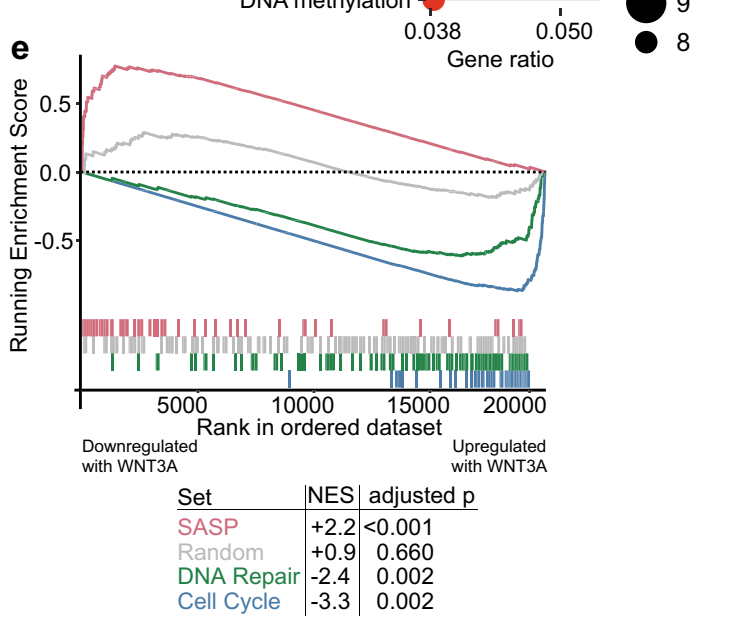

d up: $P 1 \rightarrow P 4$ (vehicle) \& down: WNT3A vs. vehicle (P4)

Oxidative Stress Induced Senescence Senescence-As. Secretory Phenotype -

DNA Damage Induced Senescence -

Pre-NOTCH Transcription \& Translation -

Diseases of programmed cell death -

Pre-NOTCH Expression \& Processing -

Packaging Of Telomere Ends DNA methylation

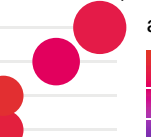

adjusted $\mathrm{p}$ $-2 \times 10^{-4}$
$-4 \times 10^{-4}$
$-6 \times 10^{-4}$ genes 

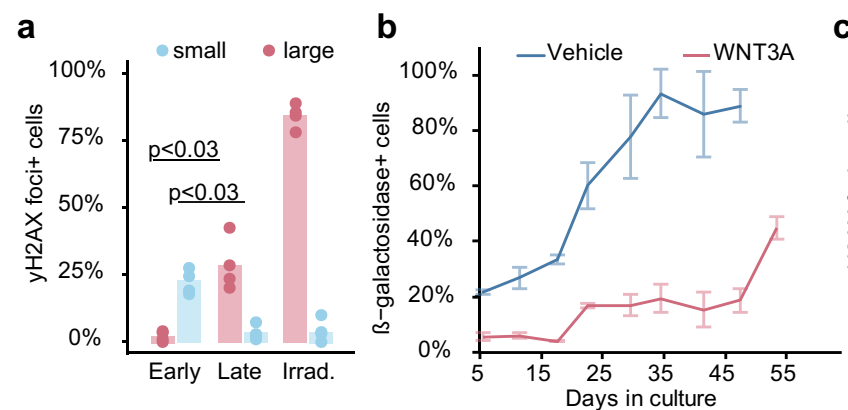

$\mathbf{f}$
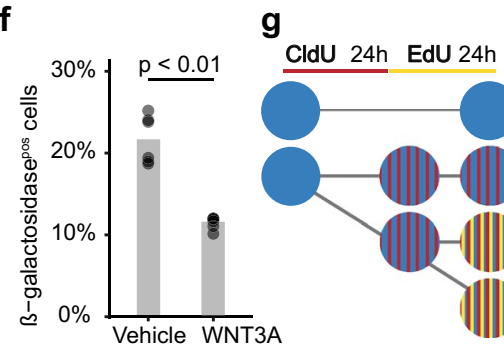

h

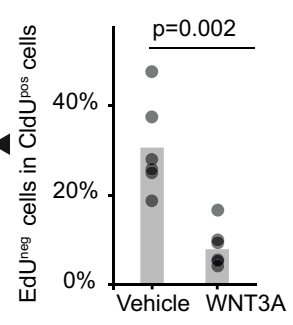

Fig. 2 WNT3A reduces the frequency of entry into senescence. a Percentage of MSCs with small or large $\gamma \mathrm{H} 2 \mathrm{AX}$ foci after expansion for two to three passages (early) or seven to nine passages (late) or after irradiation. $n=4$ donors, Mann-Whitney-Wilcoxon test. See supplemental Fig. 2a for micrographs of small and large foci. b Percentage of cells positive for $\beta$-galactosidase in MSC populations expanded with WNT3A or vehicle over ten passages. Error bars $=S D, n=3$ wells. Cells split from one untreated culture at day 0 . c Percentage of MSCs with small $(<<2 \mu \mathrm{m})$ or large $(>2 \mu \mathrm{m})$ $\gamma \mathrm{H} 2 \mathrm{AX}$ foci after expansion for two passages in vehicle or WNT3A. $n=3$ wells. Percentage of MSCs that stain d negative for EdU (24-h

break repair [50]. Late passage MSCs showed significant accumulation of cells displaying large $\gamma \mathrm{H} 2 \mathrm{AX}$ foci, associated with non-resolved DNA damage and the SASP $[6,51]$, and loss of cells displaying small foci, linked to DNA damage repair after proliferation-associated replication fork collapse (Fig. 2a, Supplementary Fig. 2a). This suggests that non-cycling cells accumulate during culture. Furthermore, we observed a rapid accumulation of cells expressing senescence-associated lysosomal $\beta$-galactosidase, an endogenous marker of senescence [52, 53] (Fig. 2b and Supplementary Fig. 2b,c). The percentage of $\beta$-galactosidase-positive cells correlated strongly with the simultaneous decline in proliferation rate over time (Supplementary Fig. 2d). WNT3A counteracted both the elevation in $\gamma \mathrm{H} 2 \mathrm{AX}$-positive cells in late passage MSCs (Fig. 2c) and the accumulation of $\beta$-galactosidase-positive cells during culture (Fig. 2b and Supplementary Fig. 2b, c). Consistent with this, expression of cell cycle arrest marker CDKN1A (encoding the CDK inhibitor p21) was reduced in cells expanded with WNT3A (Supplementary Fig. 2e). Together, these data indicate that WNT3A

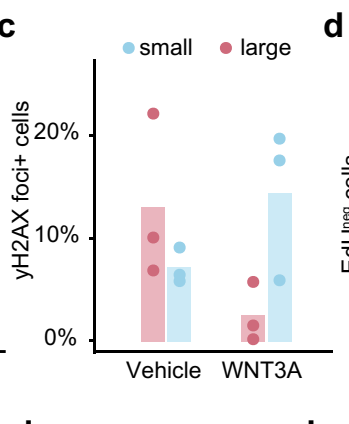

d

e

i

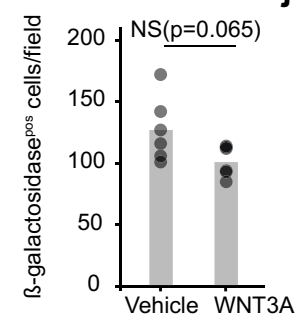

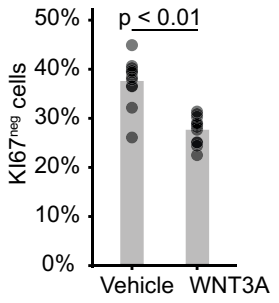

k

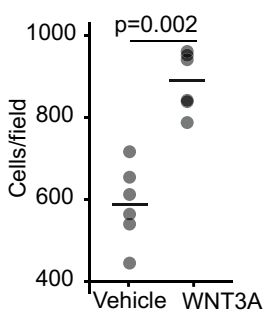

pulse) ( $n=6$ wells), e negative for Ki67 ( $n=12$ wells) or $\mathbf{f}$ positive for $\beta$-galactosidase $(n=6$ wells) after culture with WNT3A or vehicle for 6 days. $\mathbf{g}$ Experimental scheme for (h). $\mathbf{h}$ Percentage of cells negative for EdU (after 24-h labelling with EdU) within the population of cells positive for CldU (after 24-h labelling with CldU the day before) for MSCs cultured three passages with WNT3A or vehicle, respectively. $n=6$ wells, Mann-Whitney-Wilcoxon test. I-k Absolute number of $\mathbf{i}$ $\beta$-galactosidase-positive, $\mathbf{j}$ EdU-negative (24-h pulse) and $\mathbf{k}$ total cells after 6 days treatment with WNT3A or vehicle. $n=6$ wells, MannWhitney-Wilcoxon test

counteracts cell cycle exit and entry into senescence of expanding MSCs.

To confirm these findings, we analysed the cell cycle dynamics of MSCs using thymidine analogue 5-Ethynyl2'-deoxyuridine (EdU), which cells incorporate during DNA synthesis. First, we observed that early passage, WNT3A treated MSC populations undergo approximately 0.92 doublings/day (Supplementary Fig. 2f), which given losses from plating the cells suggests that the average cell cycle time is less than $24 \mathrm{~h}$. This was corroborated by EdU labelling as the percentage of EdU-labelled cells rapidly increased during the first $24 \mathrm{~h}$ of labelling but then levelled off (Supplementary Fig. 2 g), suggesting that cycling cells had incorporated EdU within $24 \mathrm{~h}$. WNT3A drastically lowered the accumulation of EdU-negative, non-cycling cells over a sixday culture period (Fig. 2d). In line with this result, WNT3A also counteracted the accumulation of cells lacking the proliferation marker Ki67 [54] (Fig. 2e). The percentage of noncycling cells closely reflected the number of $\beta$-galactosidasepositive cells (Fig. $2 \mathrm{~d}-\mathrm{f}$ ), suggesting they were senescent rather than quiescent cells, which remain $\beta$-galactosidasenegative [55]. The induction of senescence rather than quiescence was further supported by the upregulation of 
Fig. 3 WNT represses senescence in a cell non-autonomous manner. a-c MSC clones obtained from a single biopsy cultured in vehicle (blue) or WNT3A (red) for one passage and analysed for a percentage of $\beta$-galactosidase-positive cells $(n=3$ wells, error bars is $S D)$ b doubling rate $(\mathrm{n}=1)$ or c forward scatter as a measure for cell size $(n=3$ technical replicates, error bars is $S D$; nd: not determined due to insufficient cells in vehicle). d, e The expansion rate of MSC clones in WNT3A as fold of their expansion rate in vehicle, plotted against the $\mathbf{d}$ percentage of $\beta$-galactosidase-positive cells and $\mathbf{e}$ doubling rate in vehicle.

$R$ s Spearman's rank correlation coefficient
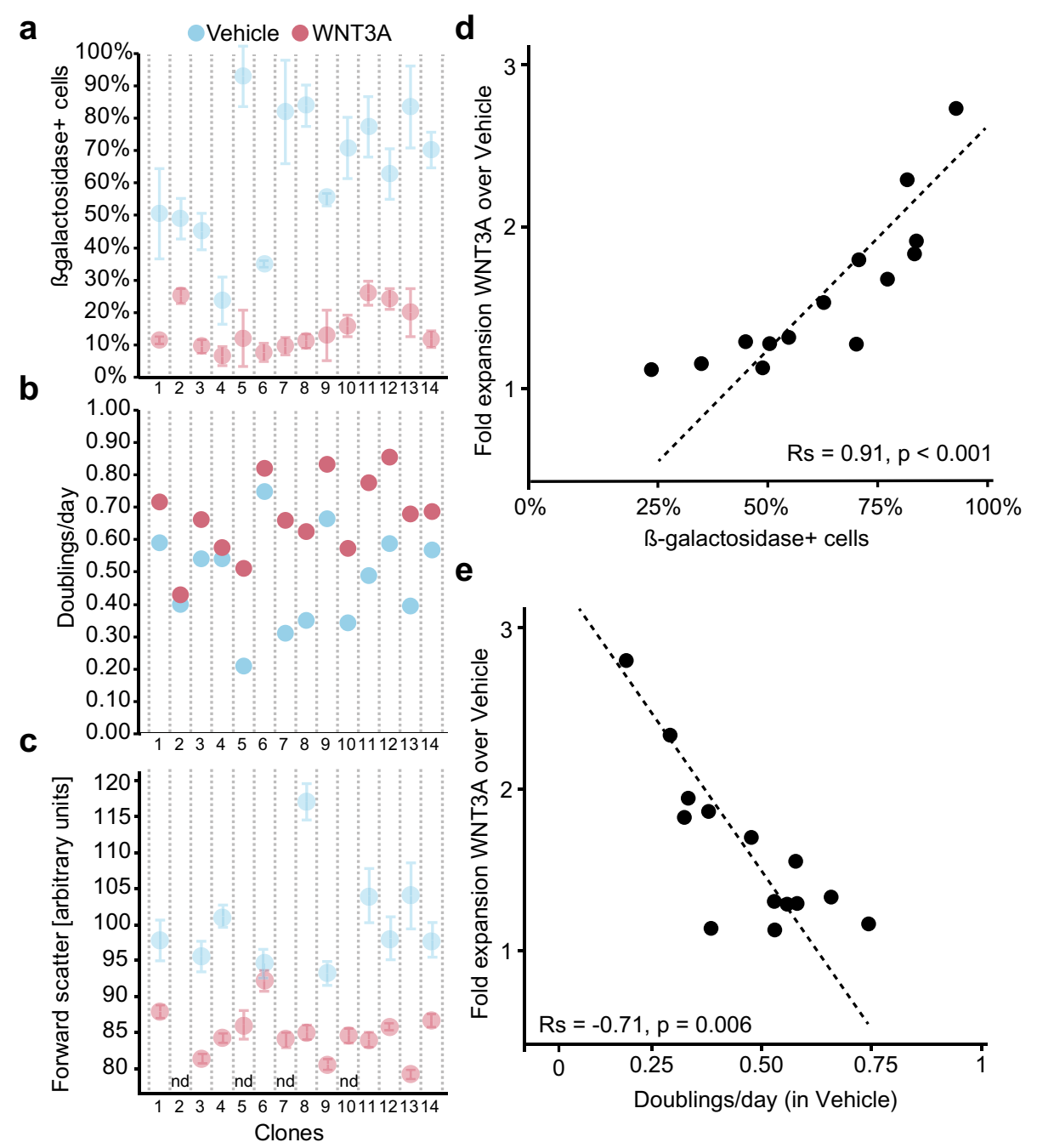

e

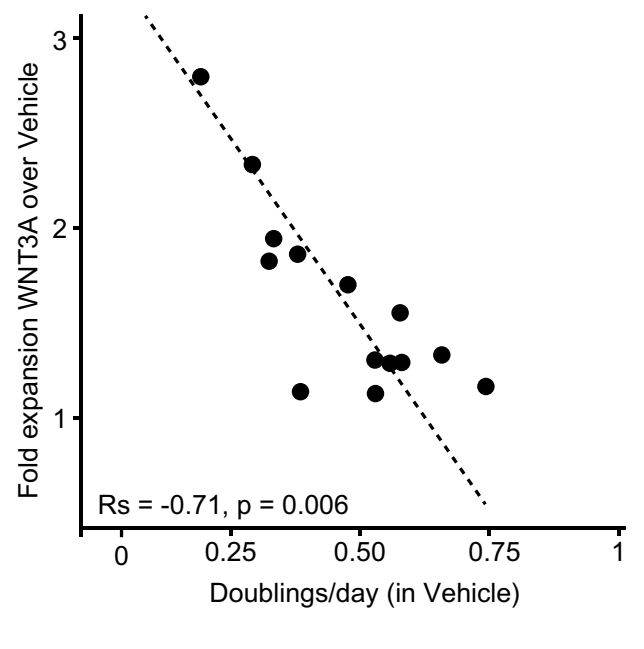

senescence-associated but not quiescence-associated genes (set based on [56, 57]) (Supplementary Fig. 2 h). By labelling cycling cells for $24 \mathrm{~h}$ with 5-Chloro-2-deoxyuridine (CldU), another thymidine analogue, followed by a $24-\mathrm{h}$ labelling with EdU, we identified how many of those cycling cells continued cycling for a second day (as illustrated in Fig. 2g). We found that $31 \%$ of MSCs expanded for three passages exited the cell cycle within these two days, while in the presence of WNT3A only $9 \%$ of MSCs did so (Fig. 2h). As a result, the absolute number of senescent cells after six days was lower in the presence of WNT3A (Fig. 2i, j), while the total cell number was significantly increased (Fig. 2k). Altogether, these data indicate that WNT3A significantly reduces the frequency at which cells exit the cell cycle and enter into senescence, thereby maintaining expansion of the population.

\section{WNT/ $\beta$-catenin signalling represses the senescence-inducing secretome of MSCs}

Cells can be induced to senesce by replication-based telomere shortening or other cell-intrinsic damage-associated aspects [58-61]. These driver events may be counteracted by WNT signals, e.g. through induction of telomerase to extend the telomeres, as observed in embryonic stem cells and umbilical cord MSCs [62, 63]. We did however not detect telomerase reverse transcriptase (TERT) expression in MSCs, by qPCR (Supplementary Fig. 3a, b) or by mRNA sequencing, regardless of the presence of WNT3A, which argues against a mechanism based on telomere shortening. To investigate whether WNT3A reduces senescence by selectively repressing the expansion of clones with a high intrinsic tendency of entering senescence, we established fourteen MSC clones from a single biopsy and analysed in each the progressive appearance of senescence. We found that WNT3A strongly suppressed the accumulation of $\beta$-galactosidase-positive cells in all clones 

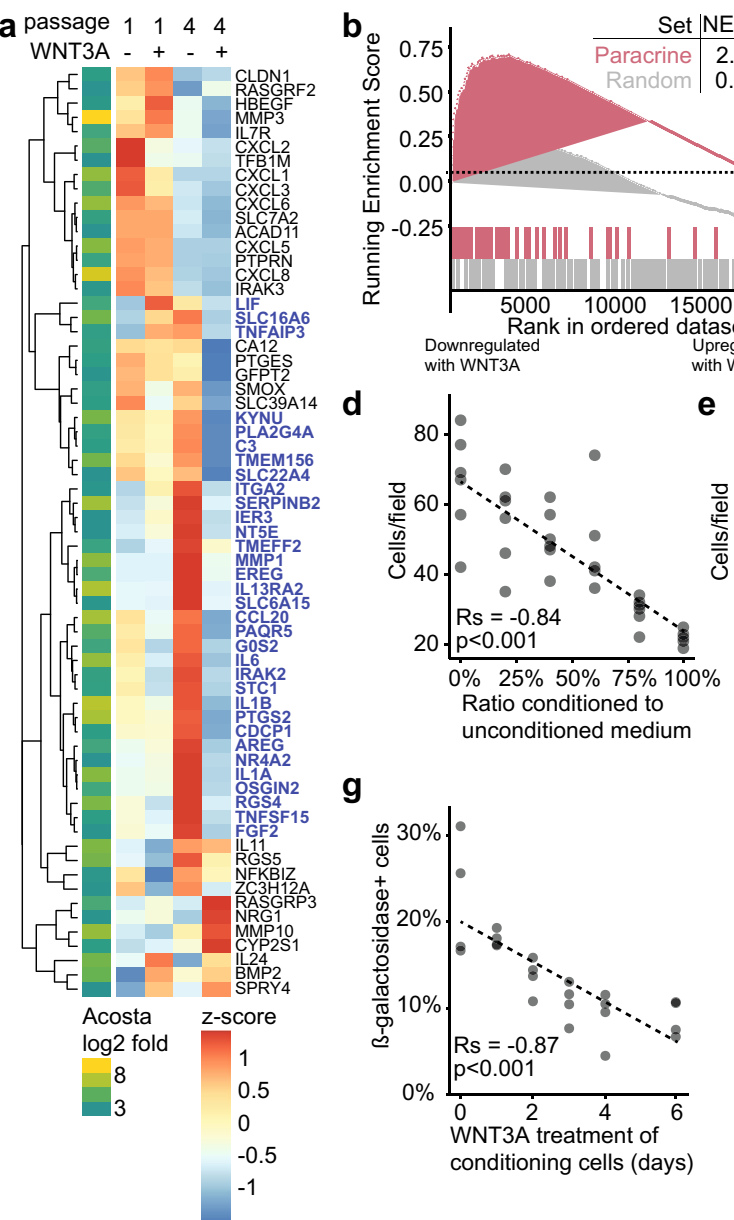

g
NES p.adj. C

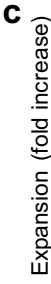

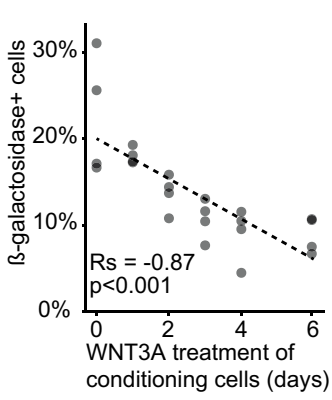

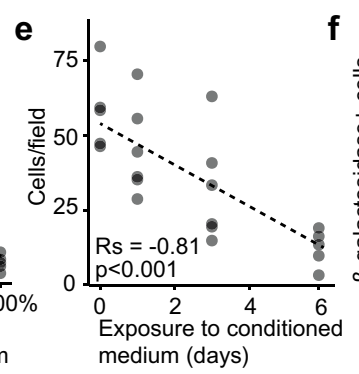

h

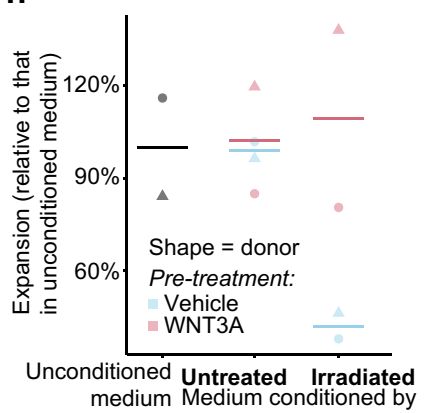

- unconditioned medium

Medium conditioned by

-- Vehicle-treated, high passage

-- WNT3A-treated, high passage

- Vehicle-treated, irradiated

-- WNT3A-treated, irradiated

Days in culture

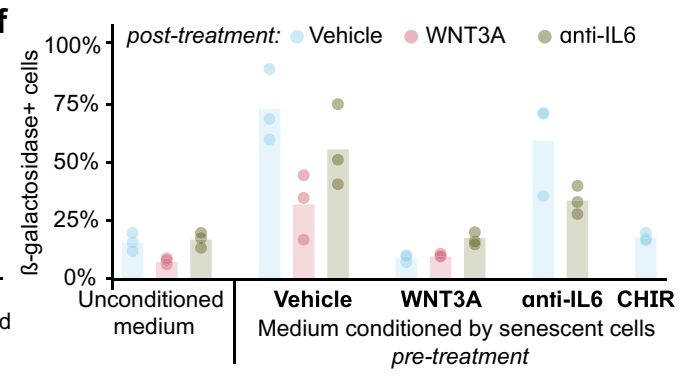

i

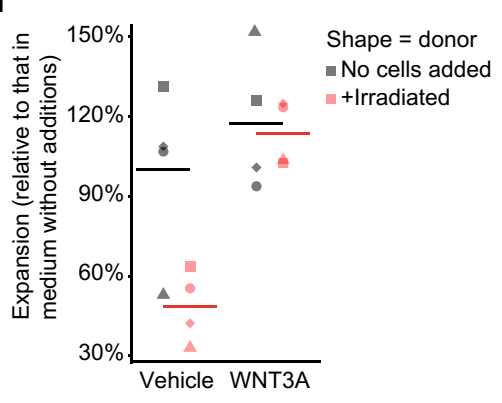

Fig. $4 \mathrm{WNT} / \beta$-catenin signalling represses paracrine senescence. a Heatmap showing the z-scored expression levels of paracrine senescence response genes at passage one and four in MSCs expanded with WNT3A or vehicle, respectively. Genes up-regulated by time in culture and down-regulated in WNT3A-expanded MSCs are highlighted in blue. Genes are hierarchically clustered according to complete linkage. The gene set is based on genes differentially expressed in fibroblasts when co-cultured with senescent or control cells according to [18], a cut-off was applied where only genes were included that were significantly $(p<0.0001)$ up-regulated for more than ten-fold. b Gene set enrichment analysis for the paracrine senescence response genes and a set of random genes with normalized enrichment score (NES) and multiple-testing adjusted (Holms-Bonferroni) $p$ values given. c Expansion of passage one MSCs in medium conditioned by MSCs rendered senescent by long-term culture or by irradiation and treated with vehicle or WNT3A or unconditioned medium not exposed to cells but otherwise processed in the same manner as conditioned medium. Error bars $=S D, n=3$ donors. d, e Cell counts for passage one MSCs after culture for $\mathbf{d} 6$ days with the indicated ratio of conditioned medium of senescent MSCs and unconditioned

(Fig. 3a), increased their proliferation rate (Fig. 3b), and prevented the cell size increase (Fig. 3c) associated with senescence [64-69]. Crucially, clones containing more senescent cells or proliferating slower showed a more pronounced increase in expansion after treatment with WNT3A (Fig. 3d, e), suggesting that WNT3A does not medium or for e six, three, one or zero days in conditioned medium of senescent MSCs with the remaining time to 6 days in unconditioned medium. $n=6$ technical replicates. $\mathbf{f}$ Percentage of $\beta$-galactosidasepositive cells in early passage MSCs cultured for 6 days in unconditioned medium or medium conditioned by senescent MSCs that were treated with WNT3A, CHIR or an IL6-neutralizing antibody, or their pooled vehicles, respectively. In addition, WNT3A, the IL6neutralizing antibody or their pooled vehicles were added together with the conditioned media to the recipient MSCs as indicated. $n=3$ donors. $\mathbf{g}$ Percentage of $\beta$-galactosidase-positive cells in early passage MSCs cultured for 6 days in medium conditioned by senescent MSCs that were treated with WNT3A for the indicated time periods. $n=4$ donors. $\mathbf{h}$ Expansion of low-senescence MSCs in unconditioned medium or medium conditioned by untreated or irradiated MSCs from the same population. Colours indicate whether the conditioning cells had been treated with WNT3A or vehicle. $n=2$ donors. i Expansion of low-senescence MSCs with or without addition of donormatched irradiated MSCs in vehicle or WNT3A. Irradiated MSCs were accordingly pre-treated with either WNT3A or vehicles before addition. $n=4$ donors

blunt the expansion of senescence-prone sub-clones. In addition, we observed that all clones kept accumulating $\beta$-galactosidase-positive cells at different rates even after 24-32 days of culture (Fig. 3a; Supplementary Fig. 3c), arguing against a cell-intrinsic model since senescence 
induced solely by intrinsic factors should co-occur within a narrow timeframe.

Senescence can also be induced through extracellular signals from the SASP of neighbouring, senescent cells [18]. To explore how WNT3A affects cell-extrinsic induction of senescence, we created a paracrine senescence gene set based on publicly available microarray data of normal fibroblasts co-cultured with fibroblasts induced into senescence by the oncogene $\mathrm{H}-\mathrm{RAS}^{\mathrm{G} 12 \mathrm{~V}}$ [18]. Interestingly, expression of the majority of genes (32/62) in this paracrine senescence gene set increased with time in culture but was strongly reduced by the presence of WNT3A (Fig. 4a, b). This suggests that WNT3A countered paracrine senescence through reducing signalling by external factors.

To test whether secreted factors induced senescence, we exposed expanding MSCs to conditioned media from high passage senescent MSCs. As expected, this suppressed expansion in a manner dependent on both dose and duration of exposure (Fig. 4c-e). Moreover, exposure to conditioned medium increased the number of $\beta$-galactosidase-positive cells (Fig. 4f). We reasoned there to be two possibilities through which WNT3A could interfere with paracrine senescence: (a) by modulating the secretome of the senescent cells or (b) by altering the response of cells to the secretome. To distinguish between these possibilities, we first treated high passage senescent cells with WNT3A and then used those cells to prepare conditioned medium (pretreated conditioned medium, which therefore did not contain added WNT3A). In addition, we prepared conditioned medium from untreated MSCs to which we added WNT3A afterwards (post-treated conditioned medium). Post-treated conditioned medium reduced, but failed to eliminate, the accumulation of $\beta$-galactosidase-positive cells (Fig. 4f). This suggests that the response to senescence-inducing factors is at least partly independent from WNT3A. Importantly, pre-treated conditioned medium did not suppress expansion and did not promote the accumulation of $\beta$-galactosidasepositive cells (Fig. 4c, f). These observations suggest that WNT3A represses the production of senescence-inducing factors by senescent MSCs.

We next observed that the pre-treated medium was more effective in suppressing the accumulation of $\beta$-galactosidasepositive cells if the WNT3A pre-treatment lasted longer (Fig. 4g). It could therefore simply be that WNT3A altered the secretome composition by eliminating the senescent cells from the conditioning population. To investigate this, we created a fully senescent population by exposing MSCs to ionizing radiation (Supplementary Fig. 4a). WNT3A treatment affected neither the fraction of senescent cells in the irradiated population nor its total cell number (Supplementary Fig. 4a, b). However, WNT3A pre-treatment altered the secretome of the irradiated population in such a way that it was no longer able to induce senescence (Supplementary Fig. 4c). These data argue that WNT3A suppressed the paracrine senescenceinducing secretome of senescent MSCs. If WNT3A enhanced the expansion of MSCs because it represses the paracrine signalling of senescent cells, then WNT3A should not affect expansion in absence of senescent cells. Addressing this posed a challenge because we observed some level of senescence and responsiveness to WNT3A in all adult MSCs that we tested (40 donors, data not shown). To overcome this problem, we used MSCs obtained from paediatric donors and from adult adipose tissue, both of which display little senescence at early passages as shown by us and others ([30, 70-72] and Supplementary Fig. 4d). Conditioned medium from these lowsenescence MSCs had no effect on expansion of recipient MSCs (Fig. 4h). In contrast, medium conditioned by these MSCs after they were irradiated to induce senescence strongly reduced expansion of the recipient cells (Fig. 4h). In line with the earlier observations, this inhibitory effect was averted when the senescent donor cells were pre-treated with WNT3A prior to media collection (Fig. 4h). Furthermore, direct addition of irradiated cells to low-senescence cultures lowered the expansion rate of the normal cells, but this too could be rescued by treatment with WNT3A (Fig. 4i).

Finally, to determine whether the effect of WNT3A on paracrine senescence was mediated by the $\mathrm{WNT} / \beta$-catenin pathway, we used the GSK3 inhibitor CHIR99021 (CHIR), which activates the $\mathrm{WNT} / \beta$-catenin pathway by preventing GSK3-mediated $\beta$-catenin degradation. Similar to WNT3A, conditioned medium from senescent MSCs treated with CHIR did not induce senescence in recipient cells (Fig. $4 f$ and Supplementary Fig. 4e). Together, these findings demonstrate that paracrine factors secreted by senescent MSCs induce entry of non-senescent MSCs into senescence, and that WNT/ $\beta$-catenin signalling interferes with the production of these factors.

\section{WNT/ $\beta$-catenin signalling represses inducers of paracrine senescence in the Senescence-associated Secretome}

Next, we explored whether SASP factors could be responsible for the paracrine induction of senescence in MSCs. Corticosteroids as well as inhibitors of NF- $\mathrm{KB}$ signalling repress a broad spectrum of SASP genes [73-75]. We found that pre-treatment of senescent cells with the corticosteroid dexamethasone as well as with the NF-kB inhibitor BAY117082 prior to conditioning reduced paracrine senescence in recipient MSCs, although less pronounced than pre-treatment with WNT3A or CHIR (Fig. 5a). Senescent MSCs expressed several SASP factors associated with paracrine senescence at a higher level, including cytokine interleukin 6 (IL6) and chemokine (C-C motif) ligand 2 (CCL2) as well as Insulin-like growth factor-binding protein (IGFBP) family members IGFBP4 and IGFBP7 [15, 76, 77] (Fig. 5b). Treatment of senescent MSCs with WNT3A or CHIR repressed 


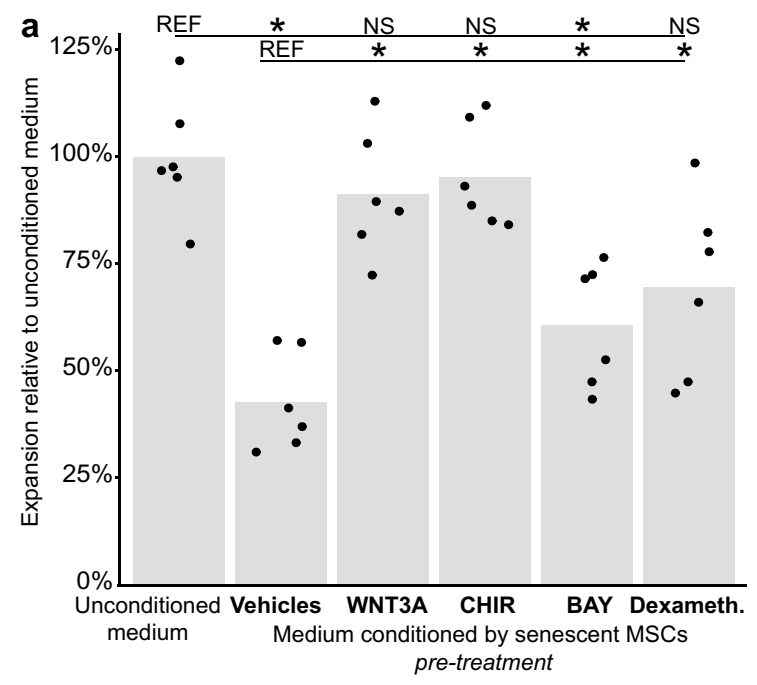

Fig. $5 \mathrm{WNT} / \beta$-catenin pathway activation represses factors mediating paracrine senescence. a Expansion of early passage MSCs cultured in medium conditioned by senescent MSCs that were treated with WNT3A, CHIR, BAY11-7082 (BAY), dexamethasone or their pooled vehicles as a fold of expansion in control medium. $n=6$ donors. Wilcoxon-Mann-Whitney test against (top line) control medium or (bottom line) conditioned medium from vehicle-treated senescent MSCs. $* p=<0.05 ; N S=p>0.05 ; p$ values vs. vehicle/control: Control (0.002/NA), BAY (0.031/0.031), dexamethasone (0.031/0.063), WNT3A (0.031/0.219), CHIR (0.031/0.688), vehicle (NA/0.002). b

this subset of SASP factors (Fig. 5c, Supplementary Fig. 5). Repression of SASP factors may therefore be a mechanism by which WNT3A prevents the paracrine induction of senescence.

Of these SASP factors, IL6 is thought to play a key role in maintaining SASP and paracrine senescence [75, 77-79]. WNT3A-expanded MSCs showed lower expression of IL6 compared to vehicle expanded MSCs (Fig. 1h, Supplementary Fig. 3b). In addition, WNT3A and CHIR each repressed IL6 expression within $24 \mathrm{~h}$ both on RNA (Fig. 5c) and protein level (Fig. 5d). We therefore investigated if interference with IL6 using an IL6-neutralizing antibody ( $\alpha$ IL6) would reduce paracrine senescence. Indeed, addition of $\alpha$ IL6 to conditioned medium from senescent MSCs reduced the induction of senescence in low passage MSCs (Fig. 4f). When both the conditioning senescent cells and the recipient cells were treated with $\alpha$ IL6, paracrine senescence was significantly reduced-albeit not completely abolished as when both donor and recipient were treated with WNT3A (Fig. 4f). The observation that WNT3A treatment reduced senescence in cells exposed to the secretome of senescent cells (Fig. 4f) might be due to WNT3A repressing secondary paracrine senescence, whereby factors inducing paracrine senescence also induce their own expression in recipient cells (see IL6 in gene set upregulated in response to SASP exposure in Fig. 4a), leading to an exponential spread of
Expression of selected SASP genes determined by QPCR for MSCs at passage four and passage seven. c Expression of selected SASP genes determined by QPCR for MSCs cultured for $24 \mathrm{~h}$ with vehicles, WNT3A or CHIR. $n=3$ donors. Expression of $\mathrm{WNT} / \beta$-catenin signalling target genes to indicate magnitude of $\mathrm{WNT} / \beta$-catenin pathway activation for these samples in Supplementary Fig. 5 d IL6 protein concentration in medium conditioned for $24 \mathrm{~h}$ by senescent MSCs after 24-h treatment with WNT3A, CHIR or their pooled vehicles. $n=3$ donors

senescence. Altogether these data indicate that WNT3A represses SASP factors, including IL6, which mediate the paracrine induction of senescence.

\section{Discussion}

The expansion and differentiation potential of MSCs decays rapidly in culture, representing a major hurdle in both research and clinical application. Here we showed that senescence spreads in MSC cultures via paracrine signalling by senescent cells displaying the SASP, leading to a selfamplifying loss of cycling cells (Fig. 6). We further demonstrated that WNT/ $\beta$-catenin signals repress SASP factors and prevent paracrine senescence induction, elucidating a hitherto unknown antagonism of senescence by the WNT pathway.

MSCs are explored for their promise for tissue engineering and the potential use of their secretome to treat inflammatory and auto-immune disorders, with 50.000 patients enrolled and 10.000 treated in clinical trials employing MSCs from 2011 to 2018 [80]. However, their limited expansion potential and rapid conversion into senescence in vitro poses major hurdles for their scale-up and successful application. The pro-inflammatory secretome of senescent MSCs interferes with applications in anti-inflammatory and 
Fig. 6 Model of the Abrogation of Paracrine Senescence by WNT/b-catenin Signalling. A cell undergoes senescence (blue) due to an endogenous trigger (red), e.g. DNA damage. Upon senescence, the cell develops the senescence-associated secretory phenotype (SASP), including factors mediating paracrine senescence, which induce senescence in surrounding cycling cells (yellow). The paracrine spread of senescence eventually renders the entire population senescent. However, activation of WNT/b-catenin signalling represses expression of the paracrine senescence mediating factors, thereby limiting the spread of senescence
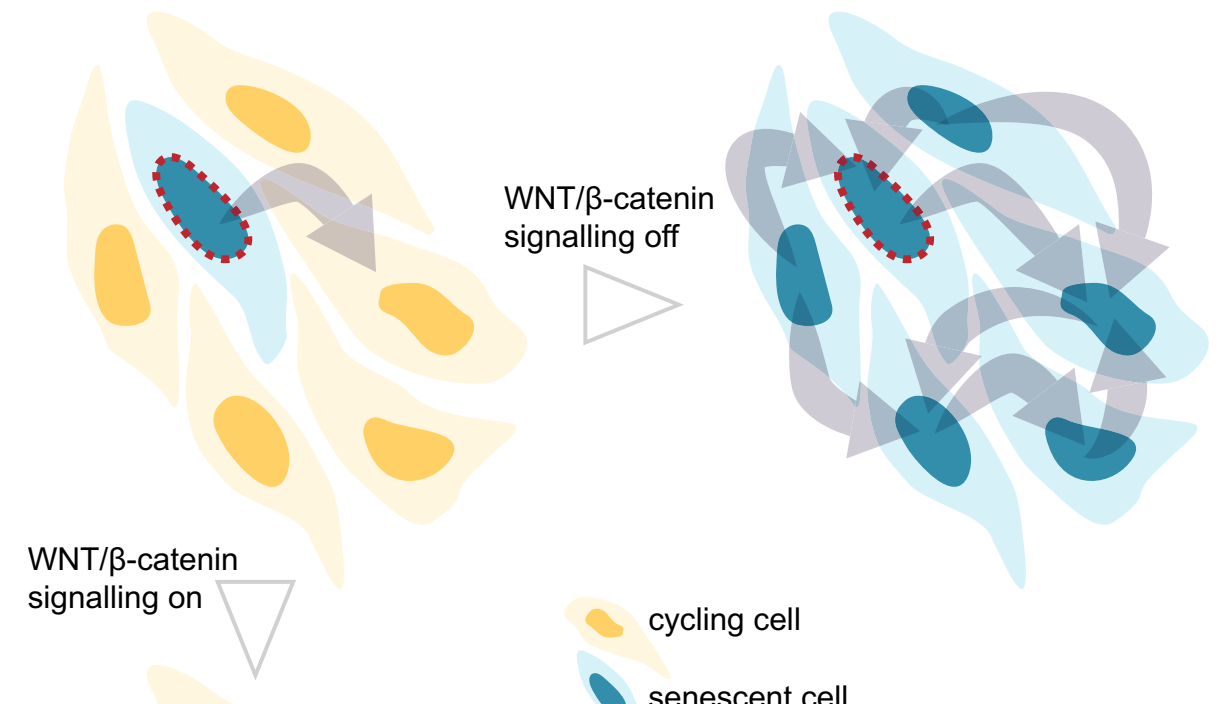

cycling cell

senescent cell

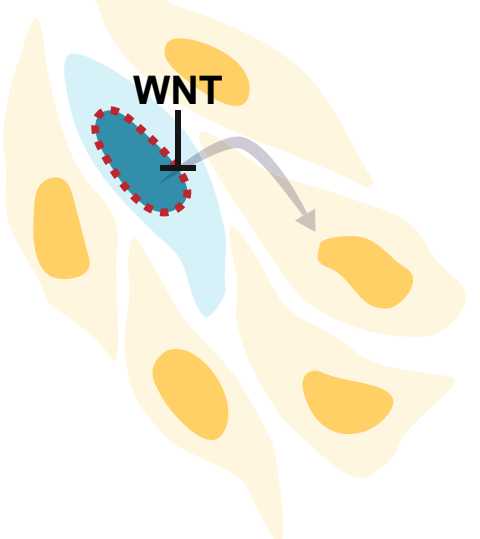

endogenous senescence trigger

paracrine signalling (SASP) autoimmune disorders [34]. Moreover, the transplantation of even a small number causes adverse systemic effects and a severe reduction in health [8]. By suppressing paracrine senescence, WNT3A might not only improve clinical applicability of MSCs by facilitating their expansion but also by lowering the proportion of senescent cells and repressing the pro-inflammatory SASP. We have previously shown that $\mathrm{WNT} / \beta$-catenin signalling agonists in combination with FGF2 maintain the differentiation potential of MSCs $[32,39]$. In light of our current findings, it is plausible that senescence drives the loss in differentiation potential over time. Indeed, differentiation is tightly linked to the cell cycle [81] and SASP growth factors and interleukins have been suggested to rewire the signalling cascades guiding differentiation [13, 82, 83]. Senescence affects other adult cells in culture including hepatocytes [84], endothelial cells [85] and $\mathrm{T}$ cells (reviewed in [86]). Counteracting senescenceinducing factors may thus be a general strategy to support cell expansion. Combinations of WNT3A with additional SASP-inhibiting factors can be explored to maximize the expansion of MSCs and other adult cells in culture. FGF2 has been reported to delay senescence in MSCs populations $[29,87,88]$ and might enhance the suppression of paracrine senescence by WNT3A (in this study all cultures were performed in the presence of exogenous FGF2). Furthermore, since WNT signals support self-renewal of many types of stem cells, counteracting senescence may have wider implications in stem cell biology.

Several studies show opposite effects of paracrine senescence and WNT signalling in neoplastic progression. While paracrine senescence limits neoplastic progression in sessile serrated adenoma and nevi $[17,18]$, WNT activation is associated with dysplasia in sessile serrated adenoma [89, 90] and delays senescence and undermines tumour suppression in nevi [91, 92]. In a murine colorectal cancer model, suppression of WNT signals induced a pro-inflammatory phenotype in cancer-associated fibroblasts and reduced tumour growth in a non-cell autonomous manner [93]. WNT signalling may therefore impact neoplastic progression by modulating the secretome of senescent cells, and the balance of paracrine senescence and WNT signalling could provide important diagnostic information, or even represent a treatment target.

Understanding the downstream mechanisms by which WNT signals repress SASP will be vital in understanding its role in stem cells and maximizing the potential of 
MSC-based therapies. Multiple studies suggest that transcription factor NF- $\mathrm{KB}$ regulates the majority of the proinflammatory SASP genes [18, 79, 94, 95]. Our findings that NF- $\mathrm{KB}$ signalling modulators suppressed paracrine senescence in MSCs suggest that WNT may repress NF- $\mathrm{kB}$ targets within the SASP set. Consistent with this, $\beta$-catenin modulates NF- $\mathrm{KB}$ signalling in a range of human cell lines by preventing NF- $\kappa \mathrm{B}$ recruitment to the chromatin [96]. Upon induction of senescence in a cancer line of mesenchymal origin (osteosarcoma, U2-OS), phosphorylation of $\mathrm{NF}-\kappa \mathrm{B}$ subunit $\mathrm{p} 65$ by GSK3 $\beta$ paves the way to a persistent SASP because it represses transcription of IкB $\alpha$, which otherwise acts as the negative feedback loop restricting NF- $\kappa$ B activity [97]. WNT3A and CHIR activate $\beta$-catenin signalling by inhibiting GSK3 activity [98] and WNT2 is repressed upon entry into oncogene-induced senescence, leading to increased GSK3 $\beta$ activity [99]. Although there is uncertainty on how GSK3 $\beta$ substrates other than $\beta$-catenin are affected by WNT ligands [98], this highlights the possibility that the repression of SASP genes we observe in response to $\mathrm{WNT} / \beta$-catenin agonists is mediated by reduced GSK3 $\beta-N F-\kappa B$ interaction. Supporting this, GSK3 $\beta$ inhibitor lithium chloride rescues $\mathrm{I} \kappa \mathrm{B} \alpha$ expression ([97]) and we have previously shown that lithium chloride activates WNT/ $\beta$-catenin signalling in MSCs and maintains their expansion [39]. Further analysis of the interaction between the WNT and NF- $\kappa B$ pathways may lead to novel options for repressing senescence and promoting expansion of adult cells.

To optimize MSC expansion, it is important to identify which SASP factors are the dominant factors mediating the population-wide paracrine spread of senescence. While we identify IL6 as a WNT-responsive contributor to paracrine senescence, several other secreted mediators for paracrine senescence in MSCs have been described: IGFBP4 and IGFBP7 in adult bone marrow MSCs, CCL2 in umbilical cord MSCs, and Pro-platelet basic protein (PPBP, also known as Neutrophil-Activating Peptide 2) and the hormone leptin in MSCs from lupus patients [15, 100, 101]. In other cell types, the most robust data suggest paracrine senescence is mediated by the IGFBP family members $[17,75$, 102-104] including the IGFBP-domain containing CCN1 (also known as IGFBP10) [105], cytokines CCL2 [18, 101], interleukin 1 beta (IL1 $\beta$ ) [19], CXCL10 [106], transforming growth factor beta (TGF $\beta)[18,19,107,108]$, the hormone prostaglandin E2 (PGE2) [109, 110], and extracellular vesicles [111]. IGFBP4 in particular has recently been suggested to mediate systemic spread of senescence: serum levels of IGFBP4 increase in response to DNA damage in humans and mice and IGFBP4 injections in mice lead to senescent cells accumulating in multiple organs, including among bone marrow MSCs [112]. We indeed found induction of
IGFBP7 and CCL2 in MSCs during culture, and their rapid repression upon treatment with WNT agonists. These factors may therefore contribute to the WNT-mediated repression of paracrine senescence in MSCs. In basal breast cancer cells, activation of WNT/ $\beta$-catenin signalling by WNT3A represses IGFBP5 (Liu et al. 2012); however, the mechanism has not been identified. Expression of IGFBPs is driven by IL6-STAT3 signalling [78] and NF- $\mathrm{KB}$ [113], and might thus respond to WNT signalling via NF- $\mathrm{KB}$ or IL6 repression. Careful analysis of the complex SASP factor network may therefore be required to assess the suitability of MSCs for therapeutic applications.

An uncontrolled paracrine spread of senescence would lead to loss of stem cells and regenerative capacity. Our findings can therefore have broader implications. The secretome of mesenchymal stromal cells in the bone marrow of aged mice induces senescence in other stromal cells, and inhibition of paracrine senescence using anti-inflammatory drugs reduces the number of senescent cells and improves bone formation [22]. Paracrine senescence is however not limited to mesenchymal cells: genetic induction of senescence in selected cells in the liver spreads to surrounding hepatocytes, resulting in liver fibrosis and impaired repair, and leading to pre-mature death in two murine liver injury models [107, 114]. WNT signals may therefore support stem cells in their niches or during regeneration not only by directly promoting their self-renewal, but also by preventing the induction of senescence-inducing factors in their environment. Since proinflammatory cytokines and TGF $\beta$ superfamily members are induced in response to tissue injury (reviewed in [115]), this mechanism might be particularly important during regenerative processes. Using WNT agonists to limit paracrine senescence after traumatic injury or genotoxic therapies may therefore provide an avenue to shield stem cell niches and encourage regeneration.

\section{Methods}

\section{Detection of for senescence-associated lysosomal $\beta$-galactosidase}

The percentage of senescent cells was determined by staining for senescence-associated lysosomal $\beta$-galactosidase using a modification of the protocol developed by [52]. Cells were washed twice in PBS, then fixed with a solution of $1 \%[\mathrm{v} / \mathrm{v}]$ formaldehyde (Sigma-Aldrich, Zwijndrecht, the Netherlands), and $0.5 \%$ glutaraldehyde [v/v] (SigmaAldrich) in PBS for $15 \mathrm{~min}$ at $4{ }^{\circ} \mathrm{C}$ and afterwards rinsed twice in distilled water. Subsequently, cells were incubated for $24 \mathrm{~h}$ at $37^{\circ} \mathrm{C}$ with ca. $250 \mu \mathrm{l}$ of staining solution per $\mathrm{cm}^{2}$ culture surface. The staining solution with a $\mathrm{pH}$ of 6.0 was made by dissolving per $\mathrm{ml}$ of distilled water $1 \mathrm{mg}$ 
$\mathrm{X}$-gal (5-bromo-4-chloro-3-indolyl- $\beta$-D-galactopyranoside) (Roche Diagnostics, Rotkreuz, Switzerland), $1.64 \mathrm{mg}$ potassium hexacyanoferrate(III) (Sigma-Aldrich), $2.1 \mathrm{mg}$ potassium hexacyanoferrate(II) trihydrate (Sigma-Aldrich), $2 \mu \mathrm{mol}$ magnesium chloride hexahydrate (Sigma-Aldrich), $150 \mu \mathrm{mol}$ sodium chloride, $7.3 \mu \mathrm{mol}$ monohydrous citric acid (Sigma-Aldrich) and $25.3 \mu \mathrm{mol}$ disbasic dodium phosphate dihydrate (Sigma-Aldrich). After incubation, the cells were rinsed twice in distilled water and either stained with 250 nM DAPI (4',6-diamidino-2-phenylindole) solution (Thermo-Fisher, Waltham, US) or counterstained using $1 \mathrm{~g} / 1$ neutral red (Sigma-Aldrich) in a solution of $0.2 \%$ acetic acid in distilled water. Subsequently, the number of cells with cyan-coloured cytoplasm, indicating $\beta$-galactosidase activity, was counted, and plotted relatively to the total number of cells.

\section{MSC cell sourcing and culture}

Human adult bone marrow-derived MSCs were isolated from femoral bone marrow aspirates of adults undergoing total hip replacement (MEC-2004-142 \& MEC-2015-644; age: 43-88, given informed consent). Human paediatric MSCs were derived from left-over iliac crest bone chips of children undergoing palate cleft reconstruction (MEC2014-16; 9-13 years, by implicit consent). The tissue utilized human tissue was procured as leftover/waste surgical material and it was reviewed and deemed exempt from full ethical review by the Erasmus MC Medical Ethical Committee under code MEC-2014-16. The protocols are in accordance with the ethical standards of our institution and with the 1964 Helsinki declaration and its later amendments or comparable ethical standards. Parents/guardians stated that they did not have any objection to the use of this tissue.

Bone chips were swirled twice in $10 \mathrm{ml}$ expansion medium and the medium than plated in $175 \mathrm{~cm}^{2}$ culture flasks, whereas bone marrow aspirates were diluted with expansion medium to $20 \mathrm{ml}$ and plated in $175 \mathrm{~cm}^{2}$ culture flasks. MSCs expansion medium consisted of: MEM- $\alpha$ (Gibco brand, Thermo-Fisher), containing 10\% heatinactivated FCS (Gibco brand, Thermo-Fisher), $50 \mu \mathrm{g} / \mathrm{mL}$ gentamicin (Invitrogen Life Technologies brand, ThermoFisher), $1.5 \mu \mathrm{g} / \mathrm{ml}$ amphotericin B [Fungizone ${ }^{\mathrm{TM}}$ ] (Invitrogen Life Technologies brand, Thermo-Fisher), $10^{-4} \mathrm{M}$ L-ascorbic acid 2-phosphate (Sigma-Aldrich) and $1 \mathrm{ng} /$ mL Fibroblast Growth Factor 2 [FGF2] (R\&D Systems, Minneapolis, USA ems). After $24 \mathrm{~h}$, the flasks were gently washed with PBS containing 1\% FCS and adherent cells expanded in expansion medium, refreshed every three days, till ca. $80 \%$ confluence. Afterwards cells were passaged to 2300 cells $/ \mathrm{cm}^{2}$ into expansion medium. When indicated, $250 \mathrm{ng} / \mathrm{ml}$ purified recombinant mouse WNT3A, made in house by genetically modified Schneider Drosophila melanogaster $\mathrm{S} 2$ cells or its vehicle 3-[(3-Cholamidopropyl) dimethylammonio]-1-propanesulfonate hydrate (CHAPS) (Sigma-Aldrich) were added to the medium. Medium was now refreshed daily, and cells passaged when reaching ca. $80 \%$ confluence. In all conditions, the expansion medium contained $1 \mathrm{ng} / \mathrm{mL}$ FGF2.

Adipose tissue-derived MSCs were isolated from human subcutaneous abdominal adipose obtained as waste material from female donors (age 46-52 years) with approval by the Medical Ethical Committee of the Erasmus MC (MEC-2014-092, by implicit consent). The adipose tissue was digested with collagenase type I (Gibco brand, Thermo-Fisher) for $1 \mathrm{~h}$, then centrifuged and washed to remove adipocytes. Subsequently the pellet was suspended in Dulbecco's Modified Eagle Medium with $1 \mathrm{~g} / \mathrm{l}$ glucose (LG-DMEM; Gibco brand, Thermo-Fisher), filtered through a $100 \mu \mathrm{m}$ strainer and plated in expansion medium. Upon $80 \%$ confluence, the cells were passaged and cultured under the same conditions as bone marrow-derived MSCs.

\section{EdU/CldU staining}

To estimate cycling cells, cultures were treated with EdU for the indicated time points and then stained using the baseclick $^{\mathrm{TM}}$ EdU-Click 488 kit (Sigma-Aldrich) according to manufacturer's instructions. Cells were cultured on glass cover slips $(18 \mathrm{~mm} \varnothing)$ for at least $24 \mathrm{~h}$ before beginning of the assay and seeded at a density so that at the end of the assay cells remained sub-confluent in the condition with the most rapid expansion. EdU was added to a final concentration of $10 \mu \mathrm{M}$ to the medium. For $>24-\mathrm{h}$ EdU pulses in experiments with daily refreshment, EdU was added to the fresh medium to be added to the cells. If the EdU pulse was below $24 \mathrm{~h}$ or in experiments on conditioned medium effects, where refreshment was not daily, the EdU was added to the medium already on the cells so that the next refreshment would coincide with cell harvest. After the indicated time points, the medium was aspirated, and the cells washed in PBS. Cells were then fixed with 3.7\% formaldehyde, washed with PBS containing 3\% BSA (Sigma-Aldrich) [wash solution] and, permeabilized with $0.5 \%$ Triton $\mathrm{X}-100$ in wash solution. The coverslips were then placed onto a paraffin film (Bemis, Neenah, USA) and exposed to $50 \mu$ l of reaction cocktail (consisting of deionized water, reaction buffer, catalyst solution, fluorophore 6-FAM-azide and buffer additive as per manufacturer protocol) and incubated at room temperature in a dark for $30 \mathrm{~min}$. Subsequently, the coverslips were rinsed in wash solution and anti-body-based stainings were now performed as indicated below. The coverslips were rinsed in distilled water and stained with a $250 \mathrm{nM}$ DAPI solution for $5 \mathrm{~min}$. Coverslips were mounted onto slides in a mounting solution (90\% glycerol (Sigma-Aldrich), 10\% 
PBS, $50 \mu \mathrm{g} / \mathrm{ml}$ gentamycin, $1.5 \mu \mathrm{g} / \mathrm{ml}$ amphotericin B) and affixed using non-fluorescent nail polish.

To identify cells exiting cell cycle, cells were first labelled with $10 \mu \mathrm{M}$ CldU for $24 \mathrm{~h}$, then the medium aspirated and the wells washed thrice with PBS and subsequently cultured with $10 \mu \mathrm{M}$ EdU for further $24 \mathrm{~h}$. The cells were then first stained using the baseclick ${ }^{\mathrm{TM}}$ EdU-Click 488 kit as described above, then stained using a rat-anti-BrDU antibody also recognizing CldU (BU1/75, Biotechne, Abingdon, UK), washed twice with PBS and stained with a goat-antirat Alexa594-tagged antibody (Abcam, Cambridge, UK). To denature the DNA for CldU staining, a treatment with $2 \mathrm{M} \mathrm{HCl}$ (Sigma-Aldrich) for $60 \mathrm{~min}$ at $37^{\circ} \mathrm{C}$ was inserted into EdU staining protocol after fixation but before permeabilization. We verified that denaturation had no effect on EdU staining quality, that the EdU detection kit did not stain CldU-only labelled cells and that staining of EdU-only labelled cells with the CldU antibody was minimal.

\section{Immunocytochemistry}

Cells were cultured on coverslips, then fixed and permeabilized as described for the EdU staining. Subsequently, cells were stained with either $2.5 \mu \mathrm{g} / \mathrm{ml}$ mouse-anti-Ki67 (Clone B56; BD Pharmingen, Franklin Lakes, USA) antibody or $1 \mathrm{ug} / \mathrm{ml}$ mouse-anti- $\gamma \mathrm{H} 2 \mathrm{AX}$ [phospho S139] antibody (clone JBW30; Millipore brand, Sigma-Aldrich) in PBS with 3\% BSA for $2 \mathrm{~h}$, rinsed twice in PBS with $0.5 \%$ Triton X-100, then stained with a goat-anti-mouse Alexa594-tagged antibody (Abcam) for $1 \mathrm{~h}$ and rinsed twice with twice in PBS with $0.5 \%$ Triton X-100. Coverslips were washed in deionized water, stained DAPI and mounted as indicated above. The positive control for $\gamma \mathrm{H} 2 \mathrm{AX}$ staining were MSCs irradiated with 15 Gy using a gamma source (Gammacell; Nordion, Abingdon, UK) and fixed 15 min later.

\section{Real-time PCR}

RNA was isolated using $0.1 \mathrm{ml}$ phenol/guanidine thiocyanate solution (TriPure Isolation Reagent; Sigma-Aldrich) per $\mathrm{cm}^{2}$ culture surface with $5 \mu \mathrm{g} / \mathrm{ml}$ glycogen (Roche Diagnostics) added to improve yield. The solution of lysed cells was then homogenized by pipetting, incubated for $15 \mathrm{~min}$ at RT, and RNA isolated using a chloroform-ethanol extraction according to the TriPure Isolation Reagent protocol. Subsequently, the concentration of RNA was estimated using a spectrophotometer (NanoDrop 8000; Isogen Life Science B.V, De Meern, the Netherlands) at 260 and $280 \mathrm{~nm}$ and the RNA treated with amplification grade deoxyribonuclease I (Invitrogen brand, Thermo-Fisher) to remove DNA. The SuperScript ${ }^{\mathrm{TM}}$ II Reverse Transcriptase kit (Invitrogen brand, Thermo-Fisher) was used according to manufacturer's instructions to synthetize cDNA, using Oligo(dT)s and a purified dNTP mix (Thermo-Fisher). Real-time PCR reactions were run using the platinum taq DNA polymerase kit (Invitrogen brand, Thermo-Fisher) according to manufacturer's instructions on a combined thermal cycler/detection system (CFX96Touch, Biorad, Hercules, USA) using SYBR-Green (Thermo-Fisher) to quantify nucleic acid concentration. Primers were picked from the PrimerBank database (https://pga.mgh.harvard.edu/primerbank/) [116] and validated in house.

Table with Primers.

\begin{tabular}{|c|c|c|c|}
\hline Gene & PrimerBank ID & $\begin{array}{l}\text { Forward } \\
\text { Primer }\end{array}$ & Reverse Primer \\
\hline GAPDH & $378404907 \mathrm{c} 1$ & $\begin{array}{c}\text { GGAGCGAGA } \\
\text { TCCCTC } \\
\text { CAAAAT }\end{array}$ & $\begin{array}{l}\text { GGCTGTTGT } \\
\text { CATACTTCT } \\
\text { CATGG }\end{array}$ \\
\hline ACTB & $312176409 \mathrm{c} 1$ & $\begin{array}{l}\text { ACCGGGCAT } \\
\text { AGTGGT } \\
\text { TGGA }\end{array}$ & $\begin{array}{l}\text { ATGGTACAC } \\
\text { GGTTCTCAA } \\
\text { CATC }\end{array}$ \\
\hline HPRT1 & $164518913 \mathrm{c} 1$ & $\begin{array}{c}\text { CCTGGCGTC } \\
\text { GTGATT } \\
\text { AGTGAT }\end{array}$ & $\begin{array}{l}\text { AGACGTTCA } \\
\text { GTCCTGTCC } \\
\text { ATAA }\end{array}$ \\
\hline AXIN2 & $195927058 \mathrm{c} 1$ & $\begin{array}{l}\text { CAACACCAG } \\
\text { GCGGAA } \\
\text { CGAA }\end{array}$ & $\begin{array}{l}\text { GCCCAATAA } \\
\text { GGAGTGTAA } \\
\text { GGACT }\end{array}$ \\
\hline TERT & $301129199 \mathrm{c} 1$ & $\begin{array}{l}\text { AAATGCGGC } \\
\text { CCCTGT } \\
\text { TTCT }\end{array}$ & $\begin{array}{l}\text { CAGTGCGTC } \\
\text { TTGAGG } \\
\text { AGCA }\end{array}$ \\
\hline IL6 & $224831235 \mathrm{c} 1$ & $\begin{array}{l}\text { ACTCACCTC } \\
\text { TTCAGA } \\
\text { ACGAATTG }\end{array}$ & $\begin{array}{l}\text { CCATCTTTG } \\
\text { GAAGGTTCA } \\
\text { GGTTG }\end{array}$ \\
\hline IGFBP4 & 10835021a1 & $\begin{array}{c}\text { GGTGACCAC } \\
\text { CCCAAC } \\
\text { AACAG }\end{array}$ & $\begin{array}{l}\text { GAATTTTGG } \\
\text { CGAAGTGCT } \\
\text { TCTG }\end{array}$ \\
\hline IGFBP5 & $171460920 \mathrm{c} 1$ & $\begin{array}{c}\text { ACCTGAGAT } \\
\text { GAGACA } \\
\text { GGAGTC }\end{array}$ & $\begin{array}{l}\text { GTAGAATCC } \\
\text { TTTGCGGTC } \\
\text { ACAA }\end{array}$ \\
\hline IGFBP7 & $359465607 \mathrm{c} 1$ & $\begin{array}{c}\text { CGAGCAAGG } \\
\text { TCCTTC } \\
\text { CATAGT }\end{array}$ & $\begin{array}{l}\text { GGTGTCGGG } \\
\text { ATTCCGATG } \\
\text { AC }\end{array}$ \\
\hline CDKN1A & $310832423 \mathrm{c} 1$ & $\begin{array}{l}\text { TGTCCGTCA } \\
\text { GAACCC } \\
\text { ATGC }\end{array}$ & $\begin{array}{l}\text { AAAGTCGAA } \\
\text { GTTCCATCG } \\
\text { CTC }\end{array}$ \\
\hline CCL2 & 4506841a1 & $\begin{array}{l}\text { CAGCCAGAT } \\
\text { GCAATC } \\
\text { AATGCC }\end{array}$ & $\begin{array}{l}\text { TGGAATCCT } \\
\text { GAACCCACT } \\
\text { TCT }\end{array}$ \\
\hline
\end{tabular}

\section{IL6 detection by ELISA}

IL6 protein concentration was measured in medium conditioned by senescent cells for $24 \mathrm{~h}$ using a solid-phase sandwich ELISA for human IL6 (DY206-05, R\&D brand, Biotechne) according to manufacturer's instructions with three technical replicates per biological sample. Serial dilutions of human recombinant IL-6 standard were included in each assay to obtain a standard curve. Absorbance was measured 
at a wavelength of $450 \mathrm{~nm}$ with wavelength correction set at $650 \mathrm{~nm}$ using a microplate reader (Bio-Rad Laboratories).

\section{Transcriptome analysis}

Bone marrow aspirates from three post-menopausal women (ages 64, 64, 73) were plated as described above and cultured for nine days in expansion medium. For transcriptome analysis (see scheme Fig. 1B), cells isolated from each donor were passaged into expansion medium without additional components $\left(10,000\right.$ cells $\left./ \mathrm{cm}^{2}\right)$, with vehicle CHAPS $\left(2300\right.$ cells $\left./ \mathrm{cm}^{2}\right)$ or with $250 \mathrm{ng} / \mathrm{ml}$ WNT3A (2300 cells/ $\mathrm{cm}^{2}$ ). After $24 \mathrm{~h}$, the flasks without additional components were switched to expansion medium with FGF2 and with CHAPS (+ vehicle) or with FGF2 and with WNT3A (+ WNT3A). After six hours, these cells (passage 1 samples) were harvested, lysed in TriPure Isolation Reagent, and RNA isolated as described above, but without addition of glycogen. Cells in the remaining two flasks were expanded with daily refreshing of the expansion medium with CHAPS or WNT3A, respectively, until $80 \%$ confluence was reached and then passaged to $2300 \mathrm{cells} / \mathrm{cm}^{2}$. MSCs were expanded in this way until expansion ceased. At passage four, WNT3A and CHAPS expanded cells were plated $\left(10,000 \mathrm{cells} / \mathrm{cm}^{2}\right)$; after $24 \mathrm{~h}$, the medium was refreshed and $6 \mathrm{~h}$ later, the cells (passage 4 samples) lysed in TriPure Isolation Reagent.

RNA sequencing library was prepared using the Trueseq kit (Illumina, Eindhoven, the Netherlands). Average amount of paired reads per sample were 30 million and sequencing was performed with an Illumina HiSeq 2000 (Illumina). Data were aligned (paired-end read, inner-mate distance $50 \mathrm{bp}$ ) to refseq human genome hg19 using TopHat \& Bowtie2. Cufflinks was used to generate gene expression levels, the UCSC refseq annotation for hg19 reference data was used as reference set and transcripts and genes were counted.

To filter transcripts with no or very low expression, only transcripts having at least 20 counts in total over all conditions were considered for further analysis. Differentially expressed genes were then determined using the $R$ package DESeq 2 for the comparisons of passage one to passage four MSCs in vehicle (referred to as change over time in culture) as well as vehicle to WNT3A cultured MSCs both at passage one (six hours of treatment) and at passage four (continuous treatment passage one to four) [117]. A list of all transcripts with their fold change as well as the adjusted (Benjamini-Hochberg/false discovery rate (FDR)) $p$ values for the aforementioned comparisons is given in supplementary file 1 . The annotated R-script used to determine differential gene expression, pathway enrichment and gene set enrichment as well as create the heatmaps shown in Figs. 1 and 4 is provided as supplementary file 4 .

\section{Pathway analysis}

Changes in pathway activity over passage in presence or absence of WNT3A were determined by selecting genes up- or down-regulated at least twofold and with a adjusted $p$ values of $<0.05$ and using the $R$ packages clusterProfiler and ReactomePA $[118,119]$ with annotation derived from the Reactome pathway database to identify significantly changes pathways (cut-off: adjusted (Benjamini-Hochberg/FDR) $p<0.001)$ [120]. Pathways and genes associated with these pathways as well as the according statistical parameters of enrichment are provided in supplementary file 2 .

\section{Gene set enrichment analysis}

Gene set enrichment analysis according to [121] was performed for the indicated five gene sets on the 20.000 genes with the highest average expression over all conditions. The data were processed using the $\mathrm{R}$ package clusterProfiler [122], employing the FGSEA method [123] and using the Holm-Bonferroni method for multiple test correction. The paracrine senescence response gene set is based on microarray data from [18] comparing gene expression between IMR90 human fibroblasts exposed to the secretome of senescent IMR90s (treated) to that of IMR90s exposed to the secretome of non-senescent IMR90s (control). We generated the gene set by selecting all genes that were significantly $(p<0.0001)$ upregulated more than ten-fold in treated over control cells. The WNT/ beta-catenin signalling pathway gene sets were sourced via the Molecular Signatures Database (UC San Diego and Broad Institute) [121, 124] and are listed below. The other gene sets are based on literature (SASP [10], paracrine senescence [18], cell cycle [44], DNA repair [45], quiescence vs. senescence [56, 125], senescence up- and downregulated genes $[48,49])$ and for convenience are provided as tables in supplementary file 3. Random gene sets were generated from a pool of all human genes (GRCh38.p13) as control matching the set size of the largest gene set analysed in an individual comparison. 


\begin{tabular}{llll}
\hline WNT/beta-catenin gene sets & & \\
\hline ID in figure & Full Name & MSigDB ID & Source \\
\hline GOBP & $\begin{array}{l}\text { Gene Ontology } \\
\text { biological pro- }\end{array}$ & M12752 & GO: 0,060,070 \\
& cess: canonical & & \\
& WNT signal- & & \\
& ling & & \\
Molecular & M5895 & MSigDB: M5895 \\
& Signatures & & \\
& $\begin{array}{l}\text { Database } \\
\text { Hallmark Gen- }\end{array}$ & & \\
& esets: WNT/ & & \\
& beta-catenin & & \\
& signalling & & \\
KEGG & Kyoto Encyclo- & M19428 & KEGG: hsa04310 \\
& pedia of Genes & & \\
& and Genomes: & \\
& WNT signal- & \\
& ling pathway & \\
\end{tabular}

\section{Paracrine senescence studies using conditioned medium}

Cells were rendered senescent either by irradiation with 80 Gray in a RS320 X-Ray machine (X-Strahl, Camberley, UK) or by culture until expansion had ceased (defined as the cell population not increasing over seven days). After irradiation, cells were cultured for at least seven days to allow senescence to occur. Senescent cells were then seeded at 20,000 cells $/ \mathrm{cm}^{2}$ with $0.2 \mathrm{ml} / \mathrm{cm}^{2}$ expansion medium and cultured at least for $24 \mathrm{~h}$ before treatment. When comparing non-senescent to senescent cells, seeding cell density was adjusted to ensure all conditions contained approximately equal cell densities at the end of treatment, which was confirmed by cell count after medium harvest.

The cells were treated with $250 \mathrm{ng} / \mathrm{ml}$ WNT3A, $12 \mu \mathrm{M}$ BAY11-7082 (BAY) (Santa-Cruz, Heidelberg, Germany), $1 \mu \mathrm{M}$ dexamethasone (Sigma-Aldrich), $3 \mu \mathrm{M}$ CHIR99021 (CHIR) (Stem Cell Technologies, Cologne, Germany), 10 ug/ml IL6-neutralizing antibody (2.11 B12) (kind gift by Frank Grosveld, Harbour Antibodies/Erasmus MC) or with the equivalent amounts of the according vehicle: CHAPS (for WNT3A), DMSO (BAY, CHIR), ethanol (dexamethasone) or PBS (IL6-neutralizing antibody). We optimized treatment duration for the different compounds-to ensure equal culture duration for cells, all conditions were cultured for 6 days, with conditions with shorter treatment duration cultured with expansion medium prior treatment so that all treatments ended on the sixth day. Treatment duration were: 6 days for WNT3A and CHIR and 3 days for BAY and dexamethasone. Non-neutralizing IL6 antibodies of the same isotype were used as controls for the neutralizing IL6 antibody. In all conditions, including pre-culture in expansion medium, refreshment was daily. At the end of treatment, cells were washed twice gently with PBS and refreshed with $0.2 \mathrm{ml} / \mathrm{cm}^{2}$ expansion medium and a control flask without cells refreshed with $0.2 \mathrm{ml} / \mathrm{cm}^{2}$ expansion medium prepared. After $24 \mathrm{~h}$, the conditioned medium was harvested, centrifuged at $300 \mathrm{~g}$ for $8 \mathrm{~min}$ and the supernatant stored. We found no difference between fresh and frozen $\left(-80{ }^{\circ} \mathrm{C}\right)$ conditioned and control medium regarding effects on proliferation and number of $\beta$-galactosidase-positive cells, therefore the supernatants were stored at $-80{ }^{\circ} \mathrm{C}$ for no more than four weeks. As control, unconditioned medium was made by incubating expansion medium for $24 \mathrm{~h}$ in a cell-free culture plate at $37{ }^{\circ} \mathrm{C}$, centrifuging at $300 \mathrm{~g}$ for $8 \mathrm{~min}$ and storing the supernatant at $-80^{\circ} \mathrm{C}$.

Recipient cells were plated at 2,300 cells $/ \mathrm{cm}^{2}$ and cultured for $24 \mathrm{~h}$ in expansion medium before being exposed to conditioned or control medium with refreshment every second day. Condition and control media were used undiluted, except in the dosage titration experiment where the two were mixed at the indicated ratios. The recipient cell cultures for all conditions were processed (analysed or passaged) simultaneously, either after the indicated time spans or when the first condition reached ca. $80 \%$ confluence (this was usually the cells cultured in unconditioned medium after 5-7 days). In the experiment where duration of exposure to conditioned medium was analysed, recipient cells were first treated for one, three or six days, with culture switching to control medium for the remaining time till 6 days. When expansion over multiple passages was analysed, recipient cell number was counted, and all conditions passaged again to 2300 cells $/ \mathrm{cm}^{2}$ into the according media.

\section{Statistical analysis and data processing}

Counting of cells for assays $(\gamma \mathrm{H} 2 \mathrm{AX}, \beta$-galactosidase, EdU, CldU, Ki67) was performed blinded by at least one experimenter (Johannes Lehmann, Natasja Franceschini, Danai Chatzivasileiou). For expansion assays, at least four samples were taken and counted per replicate to determine cell number. Statistical tests were run and data plotted using R, foremost using the ggplot2 package [126, 127]. Comparisons between groups were made using the Wilcoxon-Mann-Whitney test (two-tailed, samples not paired unless otherwise indicated), correlation was assessed based on Spearman's rank correlation coefficient. Number of replicates are given in the figure legends, when wells are indicated these are independent cultures derived from one donor, otherwise the number of donors is given.

Supplementary Information The online version contains supplementary material available at https://doi.org/10.1007/s00018-021-04035-x. 
Acknowledgements We would like to thank Joyce van Meurs for providing guidance on the design and execution of the transcriptome sequencing experiments. Moreover, we are grateful to Barbara Steurer for help with the $\gamma \mathrm{H} 2 \mathrm{AX}$ staining as well as Marjolein Baar and Nathalie van den Tempel for helpful discussions regarding the EdU labelling system. We furthermore would like to thank Julian Klein for providing suggestions on senescence assays and Sreya Basu for help with optimizing the EdU imaging procedure. Additionally, we would like to express our gratitude to Eric Farrell for facilitating access to paediatric MSCs as well as Panithi Sukho and Callie Knuth for assisting with the isolation and the culturing of adipose derived and paediatric MSCs.

Author contributions JL designed and performed experiments, analysed the data, and wrote the manuscript. RN designed experiments, assisted with their execution, and wrote the manuscript. DC, NF and WJLMK performed experiments. DtB and GJVMvO supervised the project, designed experiments, and wrote the manuscript. CGB performed transcriptome sequencing and helped designing the analysis pipeline. DP assisted with choosing and testing senescence markers and PLJdK provided guidance on experimental design. DD and RvH provided the IL6-neutralizing antibody. All authors edited the manuscript and approved the final version.

Funding This research was supported by FFG grant-CartiScaff (Gerjo van Osch), ZonMW grant 116006104 (Derk ten Berge), KWF grant UMCU7141 (Peter de Keizer).

Data availability The transcriptomics raw and processed data have been deposited in NCBI's Gene Expression Omnibus and are accessible through GEO Series accession number GSE152112. Differentially expressed genes, enriched pathways, custom gene sets derived from literature and the analysis pipeline (annotated R script) have been made available as supplementary files $1-4$.

\section{Declarations}

Conflict of interest Peter L.J. de Keizer is founder, shareholder and managing director of Cleara Biotech B.V., Utrecht, the Netherlands. Dubravka Drabek and Rien van Haperen are affiliated with Harbour Antibodies, which provided the IL6-neutralizing antibody used in this study. The remaining authors declare no competing financial or other conflicts of interests.

Ethics approval and consent to participate For collection of human tissue samples, approval was first obtained by the Medical Ethical Committee of the Erasmus MC. Human adult bone marrow-derived MSCs were isolated from femoral bone marrow aspirates of adults undergoing total hip replacement (MEC-2004-142 \& MEC-2015-644; age: 43-88, given informed consent). Human paediatric MSCs were derived from left-over iliac crest bone chips of children undergoing palate cleft reconstruction (MEC-2014-16; 9-13 years, by implicit consent). The tissue utilized human tissue was procured as leftover/waste surgical material and it was reviewed and deemed exempt from full ethical review by the Erasmus MC Medical Ethical Committee under code MEC-2014-16. Parents/guardians stated that they did not have any objection to the use of this tissue. Adipose tissue-derived MSCs were isolated from human subcutaneous abdominal adipose obtained as waste material from female donors (age 46-52 years) (MEC-2014-092, by implicit consent). The protocols are in accordance with the ethical standards of our institution and with the 1964 Helsinki declaration and its later amendments or comparable ethical standards.
Open Access This article is licensed under a Creative Commons Attribution 4.0 International License, which permits use, sharing, adaptation, distribution and reproduction in any medium or format, as long as you give appropriate credit to the original author(s) and the source, provide a link to the Creative Commons licence, and indicate if changes were made. The images or other third party material in this article are included in the article's Creative Commons licence, unless indicated otherwise in a credit line to the material. If material is not included in the article's Creative Commons licence and your intended use is not permitted by statutory regulation or exceeds the permitted use, you will need to obtain permission directly from the copyright holder. To view a copy of this licence, visit http://creativecommons.org/licenses/by/4.0/.

\section{References}

1. Campisi J, d'Adda di Fagagna F (2007) Cellular senescence: when bad things happen to good cells. Nat Rev Mol Cell Biol 8:729-740. https://doi.org/10.1038/nrm2233

2. Rodier F, Campisi J (2011) Four faces of cellular senescence. J Cell Biol 192:547-556. https://doi.org/10.1083/jcb.201009094

3. Storer M, Mas A, Robert-Moreno A et al (2013) Senescence Is a developmental mechanism that contributes to embryonic growth and patterning. Cell 155:1119-1130. https://doi.org/10.1016/j. cell.2013.10.041

4. Muñoz-Espín D, Cañamero M, Maraver A et al (2013) Programmed cell senescence during mammalian embryonic development. Cell 155:1104-1118. https://doi.org/10.1016/j.cell.2013. 10.019

5. Tsai CC, Chen YJ, Yew TL et al (2011) Hypoxia inhibits senescence and maintains mesenchymal stem cell properties through down-regulation of E2A-p21 by HIF-TWIST. Blood 117:459-469. https://doi.org/10.1182/blood-2010-05-287508

6. d'Adda di Fagagna F (2008) Living on a break: cellular senescence as a DNA-damage response. Nat Rev Cancer 8:512-522. https://doi.org/10.1038/nrc2440

7. Itahana K, Zou Y, Itahana Y et al (2003) Control of the replicative life span of human fibroblasts by p16 and the polycomb protein Bmi-1. Mol Cell Biol 23:389-401. https://doi.org/10. 1128/MCB.23.1.389-401.2003

8. Xu M, Pirtskhalava T, Farr JN, et al (2018) Senolytics improve physical function and increase lifespan in old age. Nature Medicine 1-13. https://doi.org/10.1038/s41591-018-0092-9

9. Borodkina AV, Deryabin PI, Giukova AA, Nikolsky NN (2018) "Social life" of senescent sells: What is SASP and why study it? Acta naturae 10:4-14

10. Coppé J-P, Desprez P-Y, Krtolica A, Campisi J (2010) The senescence-associated secretory phenotype: the dark side of tumor suppression. Annu Rev Pathol 5:99-118. https://doi.org/ 10.1146/annurev-pathol-121808-102144

11. Coppé J-P, Patil CK, Rodier F et al (2008) Senescence-associated secretory phenotypes reveal cell-nonautonomous functions of oncogenic ras and the p53 tumor suppressor. PLoS Biol 6:e301. https://doi.org/10.1371/journal.pbio.0060301

12. Chiche A, Le Roux I, von Joest M et al (2017) Injury-induced senescence enables in vivo reprogramming in skeletal muscle. Cell Stem Cell 20:407-414.e4. https://doi.org/10.1016/j.stem. 2016.11.020

13. Ritschka B, Storer M, Mas A et al (2017) The senescenceassociated secretory phenotype induces cellular plasticity and tissue regeneration. Genes Dev 31:172-183. https://doi.org/10. 1101/gad.290635.116

14. Demaria M, Ohtani N, Youssef SA et al (2014) An essential role for senescent cells in optimal wound healing through 
secretion of PDGF-AA. Dev Cell 31:722-733. https://doi.org/ 10.1016/j.devcel.2014.11.012

15. Severino V, Alessio N, Farina A et al (2013) Insulin-like growth factor binding proteins 4 and 7 released by senescent cells promote premature senescence in mesenchymal stem cells. Cell Death Dis 4:e911. https://doi.org/10.1038/cddis. 2013.445

16. Kortlever RM, Higgins PJ, Bernards R (2006) Plasminogen activator inhibitor- 1 is a critical downstream target of p53 in the induction of replicative senescence. Nat Cell Biol 8:878-884. https://doi.org/10.1038/ncb1448

17. Wajapeyee N, Serra RW, Zhu X et al (2008) Oncogenic BRAF induces senescence and apoptosis through pathways mediated by the secreted protein IGFBP7. Cell 132:363-374. https://doi.org/ 10.1016/j.cell.2007.12.032

18. Acosta JC, Banito A, Wuestefeld T et al (2013) A complex secretory program orchestrated by the inflammasome controls paracrine senescence. Nat Cell Biol 15:978-990. https://doi.org/10. $1038 / \mathrm{ncb} 2784$

19. Hubackova S, Krejcikova K, Bartek J, Hodny Z (2012) IL1and TGFb-Nox4 signaling, oxidative stress and DNA damage response are shared features of replicative, oncogene-induced, and drug-induced paracrine "Bystander senescence." Aging 4:932-951. https://doi.org/10.18632/aging.100520

20. Malaquin N, Carrier-Leclerc A, Dessureault M, Rodier F (2015) DDR-mediated crosstalk between DNA-damaged cells and their microenvironment. Frontiers in Genetics 6:. https://doi.org/10. 3389/fgene.2015.00094

21. Azzam EI, Little JB (2004) The radiation-induced bystander effect: evidence and significance. Hum Exp Toxicol 23:61-65. https://doi.org/10.1191/0960327104ht418oa

22. Josephson AM, Bradaschia-Correa V, Lee S et al (2019) Agerelated inflammation triggers skeletal stem/progenitor cell dysfunction. Proc Natl Acad Sci 116:6995-7004. https://doi.org/10. 1073/pnas.1810692116

23. Pittenger MF, Mackay AM, Beck SC et al (1999) Multilineage potential of adult human mesenchymal stem cells. Science (New York, NY) 284:143-147

24. Ranganath SH, Levy O, Inamdar MS, Karp JM (2012) Harnessing the mesenchymal stem cell secretome for the treatment of cardiovascular disease. Cell Stem Cell 10:244-258. https://doi. org/10.1016/j.stem.2012.02.005

25. Katsuda T, Kosaka N, Takeshita F, Ochiya T (2013) The therapeutic potential of mesenchymal stem cell-derived extracellular vesicles. Proteomics 13:1637-1653. https://doi.org/10.1002/ pmic. 201200373

26. Madrigal M, Rao KS, Riordan NH (2014) A review of therapeutic effects of mesenchymal stem cell secretions and induction of secretory modification by different culture methods. J Transl Med 12:260. https://doi.org/10.1186/s12967-014-0260-8

27. Khatab S, van Osch G, Kops N, et al (2018) Mesenchymal stem cell secretome reduces pain and prevents cartilage damage in a murine osteoarthritis model. European Cells and Materials 36:218-230. https://doi.org/10.22203/eCM.v036a16

28. Wagner W, Horn P, Castoldi M, et al (2008) Replicative senescence of mesenchymal stem cells: A continuous and organized process. PLoS ONE 3:. https://doi.org/10.1371/journal.pone. 0002213

29. Bianchi G, Banfi A, Mastrogiacomo M et al (2003) Ex vivo enrichment of mesenchymal cell progenitors by fibroblast growth factor 2. Exp Cell Res 287:98-105. https://doi.org/10.1016/ S0014-4827(03)00138-1

30. Vidal M a., Walker NJ, Napoli E, Borjesson DL (2012) Evaluation of Senescence in Mesenchymal Stem Cells Isolated from Equine Bone Marrow, Adipose Tissue, and Umbilical Cord
Tissue. Stem Cells and Development 21:273-283. https://doi. org/10.1089/scd.2010.0589

31. Galderisi U, Helmbold H, Squillaro T et al (2009) In vitro senescence of rat mesenchymal stem cells is accompanied by downregulation of stemness-related and DNA damage repair genes. Stem Cells Dev 18:1033-1042. https://doi.org/10.1089/scd.2008. 0324

32. Narcisi R, Cleary MA, Brama PAJ et al (2015) Long-term expansion, enhanced chondrogenic potential, and suppression of endochondral ossification of adult human MSCs via WNT signaling modulation. Stem Cell Rep. https://doi.org/10.1016/j.stemcr. 2015.01.017

33. Ruhland MK, Loza AJ, Capietto AH et al (2016) Stromal senescence establishes an immunosuppressive microenvironment that drives tumorigenesis. Nat Commun 7:1-18. https://doi.org/10. 1038/ncomms 11762

34. Kizilay Mancini Ö, Lora M, Shum-Tim D et al (2017) A proinflammatory secretome mediates the impaired immunopotency of human mesenchymal stromal cells in elderly patients with atherosclerosis. Stem Cells Transl Med 6:1132-1140. https://doi. org/10.1002/sctm.16-0221

35. Childs BG, Baker DJ, Wijshake T et al (2016) Senescent intimal foam cells are deleterious at all stages of atherosclerosis. Science 354:472-477. https://doi.org/10.1126/science.aaf6659

36. Jeon OH, Kim C, Laberge R-M et al (2017) Local clearance of senescent cells attenuates the development of post-traumatic osteoarthritis and creates a pro-regenerative environment. Nat Med 23:775-781. https://doi.org/10.1038/nm.4324

37. ten Berge D, Brugmann S, a, Helms J a, Nusse R, (2008) Wnt and FGF signals interact to coordinate growth with cell fate specification during limb development. Development (Cambridge, England) 135:3247-3257. https://doi.org/10.1242/dev.023176

38. Cleary MA, Osch GJVM Van, Brama PA, et al (2013) FGF, TGF $\mathrm{b}$ and Wnt crosstalk : embryonic to in vitro cartilage development from mesenchymal stem cells. https://doi.org/10.1002/term

39. Narcisi R, Arikan OH, Lehmann J et al (2016) Differential effects of small molecule WNT agonists on the multilineage differentiation capacity of human mesenchymal stem cells. Tissue Eng Part A 22:1264-1273. https://doi.org/10.1089/ten.tea.2016.0081

40. ten Berge D, Kurek D, Blauwkamp T et al (2011) Embryonic stem cells require Wnt proteins to prevent differentiation to epiblast stem cells. Nat Cell Biol 13:1070-1075. https://doi.org/10. $1038 / \mathrm{ncb} 2314$

41. Sato T, Vries RG, Snippert HJ et al (2009) Single Lgr5 stem cells build crypt-villus structures in vitro without a mesenchymal niche. Nature 459:262-265. https://doi.org/10.1038/nature07935

42. Huelsken J, Vogel R, Erdmann B et al (2001) $\beta$-Catenin controls hair follicle morphogenesis and stem cell differentiation in the skin. Cell 105:533-545. https://doi.org/10.1016/S0092-8674(01) 00336-1

43. Clevers H, Loh KM, Nusse R (2014) An integral program for tissue renewal and regeneration: Wnt signaling and stem cell control. Science 346:1248012-1248012. https://doi.org/10.1126/ science. 1248012

44. Giotti B, Chen S-H, Barnett MW et al (2018) Assembly of a parts list of the human mitotic cell cycle machinery. J Mol Cell Biol. https://doi.org/10.1093/jmcb/mjy063

45. Wood RD (2001) Human DNA repair genes. Science 291:12841289. https://doi.org/10.1126/science.1056154

46. Seluanov A, Danek J, Hause N, Gorbunova V (2007) Changes in the level and distribution of Ku proteins during cellular senescence. DNA Repair 6:1740-1748. https://doi.org/10.1016/j. dnarep.2007.06.010

47. Marthandan S, Menzel U, Priebe S et al (2016) Conserved genes and pathways in primary human fibroblast strains undergoing 
replicative and radiation induced senescence. Biol Res 49:34. https://doi.org/10.1186/s40659-016-0095-2

48. Casella G, Munk R, Kim KM et al (2019) Transcriptome signature of cellular senescence. Nucleic Acids Res 47:7294-7305. https://doi.org/10.1093/nar/gkz555

49. Hernandez-Segura A, de Jong TV, Melov S et al (2017) Unmasking Transcriptional Heterogeneity in Senescent Cells. Curr Biol 27:2652-2660.e4. https://doi.org/10.1016/j.cub.2017.07.033

50. Kinner A, Wu W, Staudt C, Iliakis G (2008) y-H2AX in recognition and signaling of DNA double-strand breaks in the context of chromatin. Nucleic Acids Res 36:5678-5694. https://doi.org/10. 1093/nar/gkn550

51. Rodier F, Coppé J-P, Patil CK et al (2009) Persistent DNA damage signalling triggers senescence-associated inflammatory cytokine secretion. Nat Cell Biol 11:973-979. https://doi.org/ 10.1038/ncb1909

52. Debacq-Chainiaux F, Erusalimsky JD, Campisi J, Toussaint O (2009) Protocols to detect senescence-associated beta-galactosidase (SA- $\beta$ gal) activity, a biomarker of senescent cells in culture and in vivo. Nat Protoc 4:1798-1806. https://doi.org/10.1038/ nprot.2009.191

53. Dimri GP, Lee X, Basile G et al (1995) A biomarker that identifies senescent human cells in culture and in aging skin in vivo. Proc Natl Acad Sci 92:9363-9367. https://doi.org/10.1073/pnas. 92.20.9363

54. Sobecki M, Mrouj K, Colinge J et al (2017) Cell-cycle regulation accounts for variability in Ki-67 expression levels. Can Res 77:2722-2734. https://doi.org/10.1158/0008-5472.CAN-16-0707

55. Alessio N, Aprile D, Cappabianca S et al (2021) Different stages of quiescence, senescence, and cell stress identified by molecular algorithm based on the expression of Ki67, RPS6, and betagalactosidase activity. Int J Mol Sci 22:3102. https://doi.org/10. 3390/ijms22063102

56. He S, Sharpless NE (2017) Senescence in health and disease. Cell 169:1000-1011. https://doi.org/10.1016/j.cell.2017.05.015

57. Wiley CD, Velarde MC, Lecot P et al (2016) Mitochondrial dysfunction induces senescence with a distinct secretory phenotype. Cell Metab 23:303-314. https://doi.org/10.1016/j.cmet.2015.11. 011

58. Simonsen JL, Rosada C, Serakinci N et al (2002) Telomerase expression extends the proliferative life-span and maintains the osteogenic potential of human bone marrow stromal cells. Nat Biotechnol 20:592-596. https://doi.org/10.1038/nbt0602-592

59. Yanada S, Ochi M, Kojima K et al (2006) Possibility of selection of chondrogenic progenitor cells by telomere length in FGF2-expanded mesenchymal stromal cells. Cell Prolif 39:575-584. https://doi.org/10.1111/j.1365-2184.2006.00397.x

60. Guillot PV, Gotherstrom C, Chan J et al (2006) Human firsttrimester fetal msc express pluripotency markers and grow faster and have longer telomeres than adult MSC. STEM CELLS 25:646-654. https://doi.org/10.1634/stemcells.2006-0208

61. Banfi A, Bianchi G, Notaro R et al (2002) Replicative aging and gene expression in long-term cultures of human bone marrow stromal cells. Tissue Eng 8:901-910. https://doi.org/10.1089/ 107632702320934001

62. Jeoung JY, Nam HY, Kwak J et al (2015) A Decline in Wnt3a signaling is necessary for mesenchymal stem cells to proceed to replicative senescence. Stem Cells and Development 24:973982. https://doi.org/10.1089/scd.2014.0273

63. Hoffmeyer K, Raggioli A, Rudloff S et al (2012) Wnt/ $\beta$-catenin signaling regulates telomerase in stem cells and cancer cells. Science (New York, NY) 336:1549-1554. https://doi.org/10.1126/ science. 1218370

64. Greenberg SB, Grove GL, Cristofalo VJ (1977) Cell size in aging monolayer cultures. In Vitro 13:297-300. https://doi.org/ 10.1007/BF02616174
65. Biran A, Zada L, Abou Karam P et al (2017) Quantitative identification of senescent cells in aging and disease. Aging Cell 16:661-671. https://doi.org/10.1111/acel.12592

66. Neurohr GE, Terry RL, Lengefeld J et al (2019) Excessive cell growth causes cytoplasm dilution and contributes to senescence. Cell 176:1083-1097.e18. https://doi.org/10.1016/j.cell.2019.01. 018

67. Yin L, Wu Y, Yang Z et al (2018) Microfluidic label-free selection of mesenchymal stem cell subpopulation during culture expansion extends the chondrogenic potential in vitro. Lab Chip 18:878-889. https://doi.org/10.1039/C7LC01005B

68. Chen Y, Mao P, Snijders AM, Wang D (2018) Senescence chips for ultrahigh-throughput isolation and removal of senescent cells. Aging Cell 17:e12722. https://doi.org/10.1111/acel.12722

69. Bertolo A, Baur M, Guerrero J et al (2019) Autofluorescence is a reliable in vitro marker of cellular senescence in human mesenchymal stromal cells. Sci Rep 9:2074. https://doi.org/10.1038/ s41598-019-38546-2

70. Knuth CA, Kiernan CH, Palomares Cabeza V, et al (2018) Isolating paediatric mesenchymal stem cells with enhanced expansion and differentiation capabilities. Tissue Engineering Part C: Methods ten.TEC.2018.0031. https://doi.org/10.1089/ten.TEC. 2018.0031

71. Søndergaard RH, Follin B, Lund LD et al (2017) Senescence and quiescence in adipose-derived stromal cells: effects of human platelet lysate, fetal bovine serum and hypoxia. Cytotherapy 19:95-106. https://doi.org/10.1016/j.jcyt.2016.09.006

72. Gruber H, Somayaji S, Riley F et al (2012) Human adiposederived mesenchymal stem cells: serial passaging, doubling time and cell senescence. Biotech Histochem 87:303-311. https://doi. org/10.3109/10520295.2011.649785

73. Laberge RM, Zhou L, Sarantos MR et al (2012) Glucocorticoids suppress selected components of the senescence-associated secretory phenotype. Aging Cell 11:569-578. https://doi.org/ 10.1111/j.1474-9726.2012.00818.x

74. Freund A, Patil CK, Campisi J (2011) p38MAPK is a novel DNA damage response-independent regulator of the senescence-associated secretory phenotype. EMBO J 30:1536-1548. https://doi. org/10.1038/emboj.2011.69

75. Kojima H, Kunimoto H, Inoue T, Nakajima K (2012) The STAT3-IGFBP5 axis is critical for IL-6/gp130-induced premature senescence in human fibroblasts. Cell Cycle 11:730-739. https://doi.org/10.4161/cc.11.4.19172

76. Hoare M, Narita M (2013) Transmitting senescence to the cell neighbourhood. Nat Cell Biol 15:887-889. https://doi.org/10. $1038 / \mathrm{ncb} 2811$

77. Kuilman T, Michaloglou C, Vredeveld LCW et al (2008) Oncogene-induced senescence relayed by an interleukin-dependent inflammatory network. Cell 133:1019-1031. https://doi.org/10. 1016/j.cell.2008.03.039

78. Kojima H, Inoue T, Kunimoto H, Nakajima K (2013) IL6-STAT3 signaling and premature senescence. JAK-STAT 2:e25763. https://doi.org/10.4161/jkst.25763

79. Alexander E, Hildebrand DG, Kriebs A et al (2013) I $\kappa B \zeta$ is a regulator of the senescence-associated secretory phenotype in DNA damage- and oncogene-induced senescence. J Cell Sci 126:3738-3745. https://doi.org/10.1242/jcs.128835

80. Pittenger MF, Discher DE, Péault BM, et al (2019) Mesenchymal stem cell perspective: cell biology to clinical progress. npj Regenerative Medicine 4:22. https://doi.org/10.1038/ s41536-019-0083-6

81. Myster DL, Duronio RJ (2000) Cell cycle: To differentiate or not to differentiate? Curr Biol 10:R302-R304. https://doi.org/ 10.1016/S0960-9822(00)00435-8 
82. de Keizer PLJ (2017) The fountain of youth by targeting senescent cells? Trends Mol Med 23:p6-17. https://doi.org/10.1016/j. molmed.2016.11.006

83. Walters HE, Yun MH (2020) Rising from the ashes: cellular senescence in regeneration. Curr Opin Genet Dev 64:94-100. https://doi.org/10.1016/j.gde.2020.06.002

84. Zhang K, Zhang L, Liu W et al (2018) In vitro expansion of primary human hepatocytes with efficient liver repopulation capacity. Cell Stem Cell 23:806-819.e4. https://doi.org/10.1016/j.stem. 2018.10.018

85. Medina RJ, O’Neill CL, O’Doherty TM et al (2013) Ex vivo expansion of human outgrowth endothelial cells leads to IL8-mediated replicative senescence and impaired vasoreparative function. Stem Cells 31:1657-1668. https://doi.org/10.1002/ stem. 1414

86. Larbi A, Fulop T (2014) From "truly naïve" to "exhausted senescent" T cells: When markers predict functionality. Cytometry A 85:25-35. https://doi.org/10.1002/cyto.a.22351

87. Eom YW, Oh J-E, Lee JI et al (2014) The role of growth factors in maintenance of stemness in bone marrow-derived mesenchymal stem cells. Biochem Biophys Res Commun 445:16-22. https://doi.org/10.1016/j.bbrc.2014.01.084

88. Coutu DL, François M, Galipeau J (2011) Inhibition of cellular senescence by developmentally regulated FGF receptors in mesenchymal stem cells. Blood 117:6801-6812. https://doi.org/10. 1182/blood-2010-12-321539

89. Yachida S, Mudali S, Martin SA et al (2009) Beta-catenin nuclear labeling is a common feature of sessile serrated adenomas and correlates with early neoplastic progression after BRAF activation. Am J Surg Pathol 33:1823-1832. https://doi.org/10.1097/ PAS.0b013e3181b6da19

90. Hashimoto T, Yamashita S, Yoshida H et al (2017) WNT pathway gene mutations are associated with the presence of dysplasia in colorectal sessile serrated adenoma/polyps. Am J Surg Pathol 41:1188-1197. https://doi.org/10.1097/PAS.0000000000000877

91. Pawlikowski JS, McBryan T, van Tuyn J et al (2013) Wnt signaling potentiates nevogenesis. Proc Natl Acad Sci USA 110:16009-16014. https://doi.org/10.1073/pnas.1303491110

92. Yeh I, Lang UE, Durieux E et al (2017) Combined activation of MAP kinase pathway and $\beta$-catenin signaling cause deep penetrating nevi. Nat Commun 8:644. https://doi.org/10.1038/ s41467-017-00758-3

93. Mosa MH, Michels BE, Menche C et al (2020) A wnt-induced phenotypic switch in cancer-associated fibroblasts inhibits EMT in colorectal cancer. Can Res 80:5569-5582. https://doi.org/10. 1158/0008-5472.CAN-20-0263

94. Chien Y, Scuoppo C, Wang X et al (2011) Control of the senescence-associated secretory phenotype by NF- B promotes senescence and enhances chemosensitivity. Genes Dev 25:2125-2136. https://doi.org/10.1101/gad.17276711

95. Salminen A, Kauppinen A, Kaarniranta K (2012) Emerging role of NF- $\mathrm{KB}$ signaling in the induction of senescence-associated secretory phenotype (SASP). Cell Signal 24:835-845. https:// doi.org/10.1016/j.cellsig.2011.12.006

96. Ma B, Fey M, Hottiger MO (2015) WNT/ -catenin signaling inhibits CBP-mediated RelA acetylation and expression of proinflammatory NF- B target genes. J Cell Sci 128:2430-2436. https://doi.org/10.1242/jcs.168542

97. Kolesnichenko M, Mikuda N, Höpken UE, et al (2021) Transcriptional repression of NFKBIA triggers constitutive IKK- and proteasome-independent $\mathrm{p} 65 /$ RelA activation in senescence. EMBO J 40:. https://doi.org/10.15252/embj.2019104296

98. Metcalfe C, Bienz M (2011) Inhibition of GSK3 by Wnt signalling - two contrasting models. J Cell Sci 124:3537-3544. https:// doi.org/10.1242/jcs.091991
99. Ye X, Zerlanko B, Kennedy A et al (2007) Downregulation of Wnt signaling is a trigger for formation of facultative heterochromatin and onset of cell senescence in primary human cells. Mol Cell 27:183-196. https://doi.org/10.1016/j.molcel.2007.05.034

100. Chen H, Shi B, Feng X et al (2015) Leptin and Neutrophil-activating peptide 2 promote mesenchymal stem cell senescence through activation of the phosphatidylinositol 3-kinase/Akt pathway in patients with systemic lupus erythematosus. Arthritis Rheumatol 67:2383-2393. https://doi.org/10.1002/art.39196

101. Jin HJ, Lee HJ, Heo J et al (2016) Senescence-associated MCP-1 secretion is dependent on a decline in BMI1 in human mesenchymal stromal cells. Antioxid Redox Signal 24:471-485. https:// doi.org/10.1089/ars.2015.6359

102. Benatar T, Yang W, Amemiya Y et al (2012) IGFBP7 reduces breast tumor growth by induction of senescence and apoptosis pathways. Breast Cancer Res Treat 133:563-573. https://doi.org/ 10.1007/s10549-011-1816-4

103. Zuo S, Liu C, Wang J et al (2012) IGFBP-rP1 induces p21 expression through a p53-independent pathway, leading to cellular senescence of MCF-7 breast cancer cells. J Cancer Res Clin Oncol 138:1045-1055. https://doi.org/10.1007/ s00432-012-1153-y

104. Elzi DJ, Lai Y, Song M et al (2012) Plasminogen activator inhibitor 1 - insulin-like growth factor binding protein 3 cascade regulates stress-induced senescence. Proc Natl Acad Sci 109:12052-12057. https://doi.org/10.1073/pnas.1120437109

105. Il JJ, Lau LF (2010) The matricellular protein CCN1 induces fibroblast senescence and restricts fibrosis in cutaneous wound healing. Nat Cell Biol 12:676-685. https://doi.org/10.1038/ncb20 70

106. Victorelli S, Lagnado A, Halim J, et al (2019) Senescent human melanocytes drive skin ageing via paracrine telomere dysfunction. The EMBO Journal 38:. https://doi.org/10.15252/embj. 2019101982

107. Bird TG, Müller M, Boulter L, et al (2018) TGF $\beta$ inhibition restores a regenerative response in acute liver injury by suppressing paracrine senescence. Science Translational Medicine 10:eaan1230. https://doi.org/10.1126/scitranslmed.aan1230

108. Shao C, Folkard M, Prise KM (2008) Role of TGF- $\beta 1$ and nitric oxide in the bystander response of irradiated glioma cells. Oncogene 27:434-440. https://doi.org/10.1038/sj.onc.1210653

109. Yang HH, Kim C, Jung B et al (2011) Involvement of IGF binding protein 5 in prostaglandin E2-induced cellular senescence in human fibroblasts. Biogerontology 12:239-252. https://doi.org/ 10.1007/s10522-010-9318-z

110. Dagouassat M, Gagliolo J-M, Chrusciel S et al (2013) The cyclooxygenase-2-prostaglandin E 2 pathway maintains senescence of chronic obstructive pulmonary disease fibroblasts. Am J Respir Crit Care Med 187:703-714. https://doi.org/10.1164/ rccm.201208-13610C

111. Borghesan M, Fafián-Labora J, Eleftheriadou O et al (2019) Small extracellular vesicles are key regulators of non-cell autonomous intercellular communication in senescence via the interferon protein IFITM3. Cell Rep 27:3956-3971.e6. https://doi.org/ 10.1016/j.celrep.2019.05.095

112. Alessio N, Squillaro T, Di Bernardo G, et al (2020) Increase of circulating IGFBP-4 following genotoxic stress and its implication for senescence. eLife 9:. https://doi.org/10.7554/eLife.54523

113. Ben-Shmuel A, Shvab A, Gavert N et al (2013) Global analysis of L1-transcriptomes identified IGFBP-2 as a target of ezrin and $\mathrm{NF}-\kappa \mathrm{B}$ signaling that promotes colon cancer progression. Oncogene 32:3220-3230. https://doi.org/10.1038/onc.2012.340

114. Ferreira-Gonzalez S, Lu WY, Raven A et al (2018) Paracrine cellular senescence exacerbates biliary injury and impairs regeneration. Nat Commun 9:1-15. https://doi.org/10.1038/ s41467-018-03299-5 
115. Eming SA, Wynn TA, Martin P (2017) Inflammation and metabolism in tissue repair and regeneration. Science 356:1026-1030. https://doi.org/10.1126/science.aam7928

116. Wang X, Spandidos A, Wang H, Seed B (2012) PrimerBank: a PCR primer database for quantitative gene expression analysis, 2012 update. Nucleic Acids Res 40:D1144-D1149. https://doi. org/10.1093/nar/gkr1013

117. Love MI, Huber W, Anders S (2014) Moderated estimation of fold change and dispersion for RNA-seq data with DESeq2. Genome Biol 15:550. https://doi.org/10.1186/s13059-014-0550-8

118. Yu G, He Q-Y (2016) ReactomePA: an R/Bioconductor package for reactome pathway analysis and visualization. Mol BioSyst 12:477-479. https://doi.org/10.1039/C5MB00663E

119. Wu T, Hu E, Xu S, et al (2021) clusterProfiler 4.0: A universal enrichment tool for interpreting omics data. The Innovation 2:100141. https://doi.org/10.1016/j.xinn.2021.100141

120. Jassal B, Matthews L, Viteri G et al (2020) The reactome pathway knowledgebase. Nucleic Acids Res 48:D498-D503. https:// doi.org/10.1093/nar/gkz1031

121. Subramanian A, Tamayo P, Mootha VK et al (2005) Gene set enrichment analysis: a knowledge-based approach for interpreting genome-wide expression profiles. Proc Natl Acad Sci 102:15545-15550. https://doi.org/10.1073/pnas.0506580102

122. Yu G, Wang L-G, Han Y, He Q-Y (2012) clusterProfiler: an R Package for Comparing Biological Themes Among Gene
Clusters. OMICS: A Journal of Integrative Biology 16:284-287. https://doi.org/10.1089/omi.2011.0118

123. Korotkevich G, Sukhov V, Sergushichev A (2019) Fast gene set enrichment analysis. bioRxiv 60012. https://doi.org/10.1101/ 060012

124. Liberzon A, Birger C, Thorvaldsdóttir $\mathrm{H}$ et al (2015) The molecular signatures database hallmark gene set collection. Cell Syst 1:417-425. https://doi.org/10.1016/j.cels.2015.12.004

125. Wiley CD, Flynn JM, Morrissey C et al (2017) Analysis of individual cells identifies cell-to-cell variability following induction of cellular senescence. Aging Cell 16:1043-1050. https://doi.org/ $10.1111 /$ acel.12632

126. R Core Team (2018) R: A Language and Environment for Statistical Computing

127. Wickham $H$ (2016) ggplot2: elegant graphics for data analysis. Springer-Verlag, New York

Publisher's Note Springer Nature remains neutral with regard to jurisdictional claims in published maps and institutional affiliations. 